$3^{22^{5}} 1^{01^{5}} / 44$

\title{
UCRL-I|387 SuppI.
}

\section{University of California}

\section{Ernest O. Lawrence Radiation Laboratory}

SUPPLEMENT TO BIOLOGY AND MEDICINE SEMIANNUAL REPORT Spring 1964

Berkeley, California 


\section{DISCLAIMER}

This report was prepared as an account of work sponsored by an agency of the United States Government. Neither the United States Government nor any agency Thereof, nor any of their employees, makes any warranty, express or implied, or assumes any legal liability or responsibility for the accuracy, completeness, or usefulness of any information, apparatus, product, or process disclosed, or represents that its use would not infringe privately owned rights. Reference herein to any specific commercial product, process, or service by trade name, trademark, manufacturer, or otherwise does not necessarily constitute or imply its endorsement, recommendation, or favoring by the United States Government or any agency thereof. The views and opinions of authors expressed herein do not necessarily state or reflect those of the United States Government or any agency thereof. 


\section{DISCLAIMER}

Portions of this document may be illegible in electronic image products. Images are produced from the best available original document. 
UCRL-11387 Suppl.

UC -48 Biology and Medicine

TID -4500 (29th Ed.)

\section{UNIVERSIT Y OF CALIFORNIA}

Lawrence Radiation Laboratory

Berkeley, California

AEC Contract No. W-7405-eng -48

SUPPLEMENT TO

BIOLOGY AND MEDICINE SEMIANNUAL REPORT

Spring 1964

Work done under the auspices of

National Aeronautics and Space Administration

National Institutes of Health

U. S. Atomic Energy Commission 
THIS PAGE

\section{WAS INTENTIONALLY LEFT BLANK}




\section{Contents}

On the Spatial Distribution of Radicals Produced by Ir radiation

S. J. Wyard

EPR Studies on $\mathrm{OH}$ Radical Identification in Irradiated $\mathrm{H}_{2} \mathrm{O}$

T. E. Gunter and C. D. Jeffries . . . . . . . . . . . 8

Electron Microscopy of Single-Stranded DNA

David Freifelder, Albrecht K. Kleinschmidt, and

Robert L. Sinsheimer . . . . . . . . . . 14

Inactivation and Recovery of Microorganisms after

Treatment with Ult raviolet Light

or Other Mutagens

Robert H. Haynes 


\section{ON THE SPATIAE-DISTRIBUTIONOOF RADICALS PRODUCED BY IRRADIATION* \\ S. J. Wyard ${ }^{\dagger}$}

Int roduction

The possibility of using electron spin resonance techniques to meas ure the spatial distribution of radicals appears to have been first suggested by Livingston, 1 in a paper given at the First International Congress of Radiation Research in 1958. However, the method has not found much application because, although radicals can be trapped in many materials in the solid state, they cannot be trapped sufficiently closely together for the ESR method to be used. The reasons for this are not known.

While working with frozen solutions of hydrogen peroxide, Dr. Smith and I discovered that this material is an exception to the rule just mentioned, and that radicals can be trapped quite close together in it .. the closest distance observed being about $4 \AA .{ }^{2}$ So frozen solutions of hydrogen peroxide provide a suitable working substance for measuring spatial distributions of radicals; and we published a preliminary report on this in $1961 .{ }^{3}$ I am at present continuing these.measurements, using the facilities provided by Professor Tobias at the Donner Laboratory; and although this work is not yet complete, I thought it mightbe of sufficient interest to give an interim report at this meeting.

\section{Method}

There is not time to go into the details of the method, but I should mention that there are in fact two methods. The first depends on the linewidth of the normal ESR spectrum at $\mathrm{g}=2$, while the second depends on the intensity of a so-called forbidden transition which occurs at $g=4$, i. e., at half the magnetic field. Both methods give essentially the same information, but it is useful to have both as a check on each other. If the radicals are distributed throughout the sample in pairs, clusters, or columns, then the method gives the average spacing between radicals within individual pairs, clusters, or columns. The spacing can be obtained from the measurements via theoretical calculations; alternatively the methods can be calibrated by producing known randomly spaced concentrations of radicals.

Figure 1 shows the buildup of radical concentration with radiation dose. At $77^{\circ} \mathrm{K}$ the radicals are stable for months. The maximum concentration of radicals shown in Fig. 1 is about $2 \%$ of the number of molecules, and the average spacing at this concentration is about $12 \AA$.

*Paper presented at the Twelfth Annual Meeting of the Radiation Research Society, Miami Beach, Florida, May 1964.

† On leave from the University of London, England. 


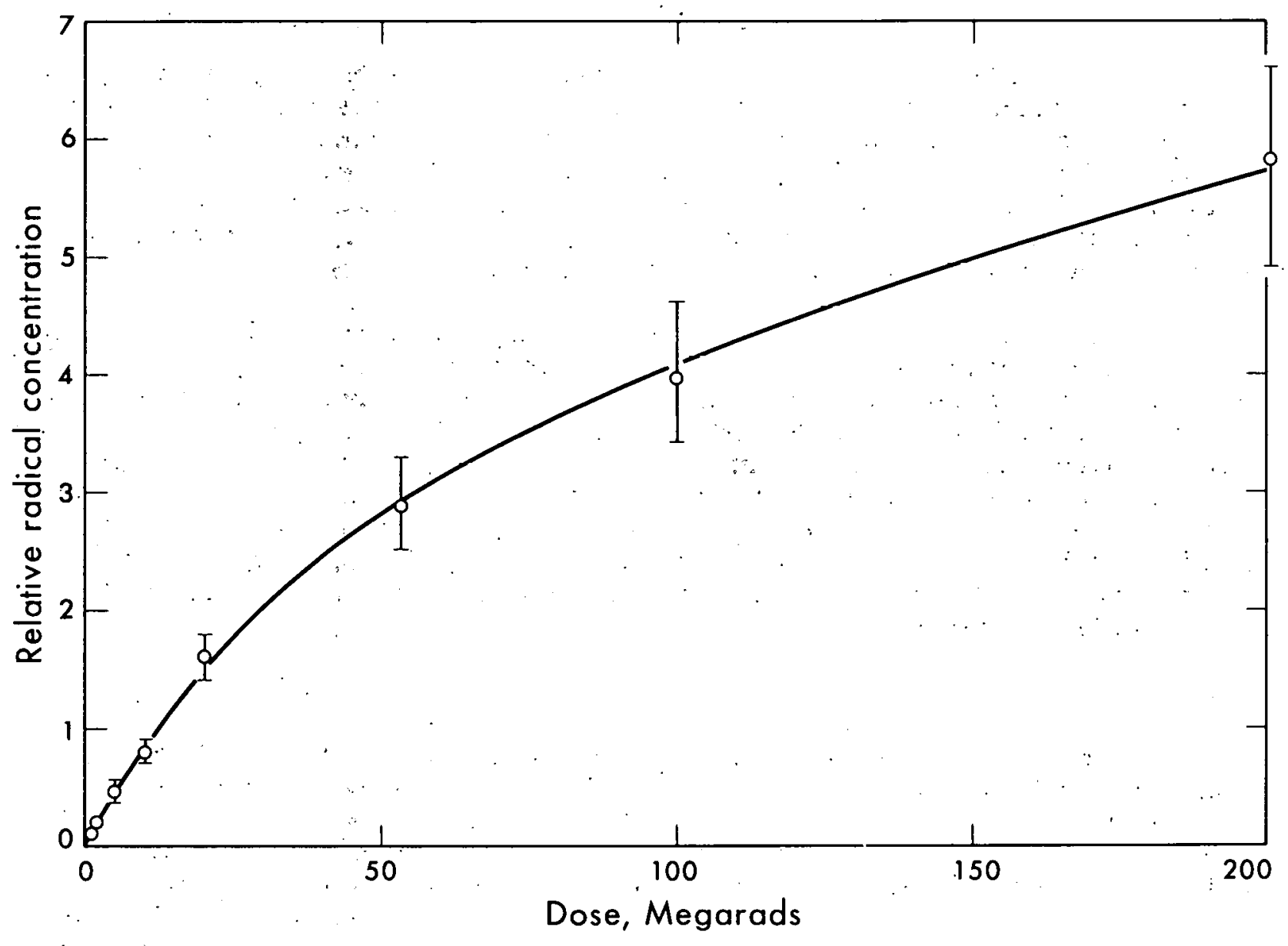

MU B-3667 Fig. 1. Dose-effect curve; $50 \% \mathrm{w} / \mathrm{w} \mathrm{H}_{2} \mathrm{O}_{2}-\mathrm{H}_{2} \mathrm{O} ; 77^{\circ} \mathrm{K}$;
6.5-MeV electrons. 
Figure 2 shows the increase in line width with radiation dose for the same conditions as Fig. 1. By comparing Figs. 1 and 2 the variation of line width with radical concentration is obtained. The separation between salient points on the spectrum can be measured with sufficient accuracy that a difference in radical concentration of $3 \times 10^{-3} \mathrm{M}$ should be detectable. However, the line shape is complex, which makes it more difficult to extract the line width, and at present the limit of resolution is about $10^{-2} \mathrm{M}$.

Figure 3 shows the ratio of intensities of the $g=4$ and $g=2$ spectra plotted against radiation dose, for the same conditions as Figs. 1 and 2 . The intercept at zero dose, which is obtained by extrapolation, gives the initial concentration of radicals in clusters. With this method the limit of resolution is also about $10^{-2} \mathrm{M}$, a figure which can probably be improved on.

The initial local concentrations may be removed by annealing the samples. The radicals diffuse rapidly at about $140^{\circ} \mathrm{K}$; annealing for a few minutes at this temperature produces a sample in which the radicals are essentially separate. Such a sample provides a base line for the measurement of line widths.

\section{$\underline{\text { Results }}$}

These methods have been used to study the spatial distribution of radicals when they are produced by either uv or ionizing radiation.

With uv radiation the radicals are produced in pairs. The average separation varies according to the conditions of radiation from about 5 to $10 \AA$. The average separation is greater with shorter-wavelength radiation (wavelengths between 3500 and $2.537 \AA$ were ysed), is greater when ir radiations are carried out at $77^{\circ} \mathrm{K}$ than at $4.2^{\circ} \mathrm{K}$, and also increases with radiation dose.

Turning to ionizing radiation, the local concentrations are the same for all the low-LET radiations used, from $6.5-\mathrm{MeV}$ electrons to $16-\mathrm{MeV}$ deuterons (average LET from 0.6 to $14 \mathrm{keV} / \boldsymbol{\mu}$ ). The local concentration is close to the limit of what can be measured, and is estimated at $0.05 \mathrm{M}$. The corresponding average separation is $32 \AA$. In an early experiment a higher local concentration was obtained by using a particles. ${ }^{3}$ This result might be criticized, because the irradiation was carried out with thorium $X$, and this introduced thorium $X$, chloride ions, and an acidic solution into the sample; these might have affected the measurements. An experiment is now in progress using heavy ions, and the results appear to confirm the aparticle experiment. Preliminary values for local concentrations using heavy ions are $0.08 \mathrm{M}$ with helium (average $\mathrm{LET} 35 \mathrm{keV} / \boldsymbol{\mu}$ ) and $0.1 \mathrm{M}$ with carbon (average $\mathrm{LE} \overline{\mathrm{T}} 310 \mathrm{keV} / \mathrm{k}$ ). 


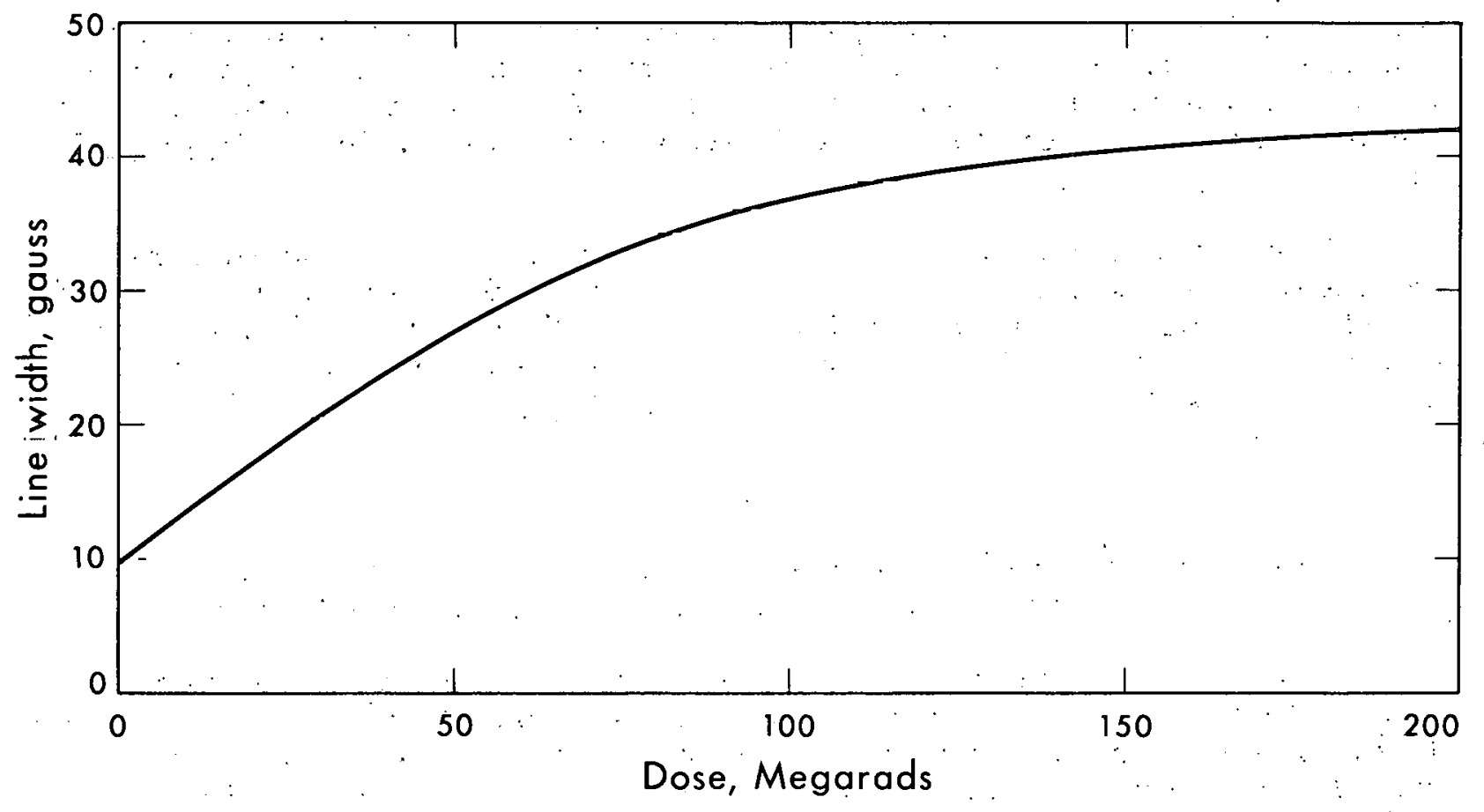

MUB-3668

Fig. 2. Line width variation; $50 \% \mathrm{w} / \mathrm{w} \mathrm{H}_{2} \mathrm{O}_{2}-\mathrm{H}_{2} \mathrm{O} ; 77^{\circ} \mathrm{K}$; 


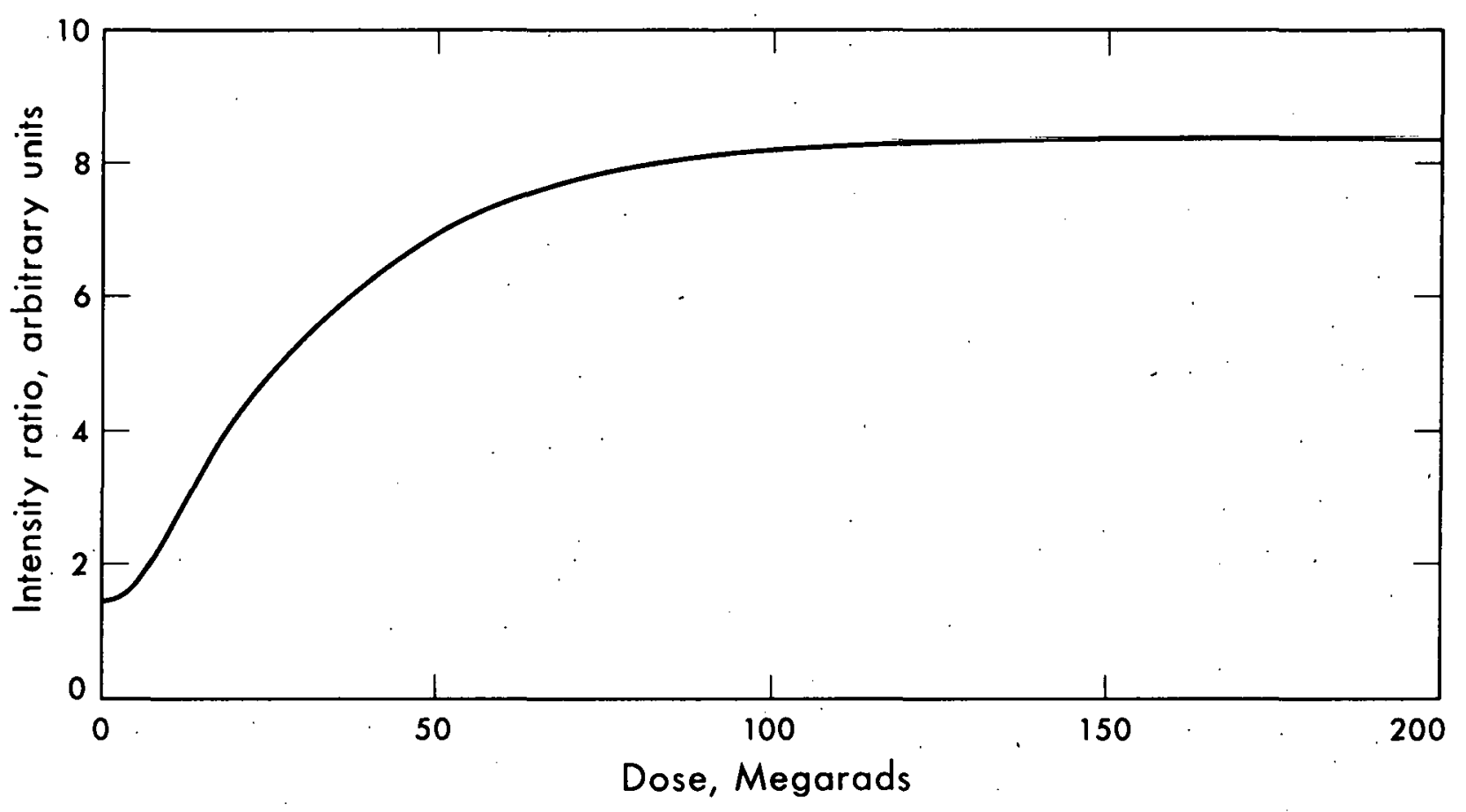

MU B-3669 Fig. 3. Intensity ratio $(\mathrm{g}=4$ to $\mathrm{g}=2) ; 50 \% \mathrm{w} / \mathrm{w} \mathrm{H}_{2} \mathrm{O}_{2}-\mathrm{H}_{2} \mathrm{O}$;
$77^{\circ} \mathrm{K} ; 6.5-\mathrm{MeV}$ electrons. 


\section{Discussion}

Taking the results for uv radiation first, the $\mathrm{H}_{2} \mathrm{O}_{2}$ molecule is split into two fragments which can possess kinetic energy equal to the difference between the quantum energy of the uv photon and the energy of the bond which has been broken. With a shorter wavelength there will be more kinetic energy, leading to a greater diffusion apart. This accounts for the observed variation in separation with wavelength. The variation in separation with temperature of the sample is also reasonable, since at $4.2^{\circ} \mathrm{K}$ the glass would be more rigid than at $77^{\circ} \mathrm{K}$, so that a given excess energy would result in less diffusion. "The increase in separation with increasing dose is more surprising; in fact, one would expect that as the concentration of radicals built up the pairs would begin to overlap, resulting in a smaller average separation: 'The fact that the opposite occurs might be explained by a, local heating effect. The yield is 1 radical for every 15 photons absorbed, so that in the majority of cases the two fragments of the photolyzed molecule recombine, and all the energy is transferred to the surrounding material in the form of heat. For glassy samples this causes a temporary softening (at $140^{\circ} \mathrm{K}$ the glass is sufficiently soft that radicals diffuse rapidly), and. would allow an existing pair of radicals in the neighborhood to diffuse a little farther apart. Another possibility is that if a pair of radicals is formed. close to an already existing pair, the two closest radicals may combine, leaving the other two farther apart.

Turning to the results for ionizing radiation, the variations of local concentrations are what one would expect, since the concentrations are low for low-LET radiations where the clusters are separated, and increase with LET above the value of LET for which the clusters begin to overlap.: However, the absolute values of concentration are quite low. The yield is of the order of 10 radicals per $100 \mathrm{eV}$; from which it may be calculated that the radicals formed by the deposition of $100 \mathrm{eV}$ occupy a volume equal to a sphere $90 \AA$ in diameter. In the radiation chemistry of water it is often assumed that a cluster or spur of radicals formed by $100 \mathrm{eV}$ occupies a sphere of about $25 \AA$ diameter. 4,5 The first possibility to consider, to account for this difference, is that the radicals are initially formed in clusters of $25 \AA$ diameter in the hydrogen peroxide glasses, but diffuse to a volume $90 \AA$ in diameter before being stabilized. The results for uv radiation, discussed above, suggest that for ionizing radiation also, the radicals are trapped a little distance from the site of the ionized molecule, but not far enough to account for the difference between 25 and $90 \AA$. Moreover, if there is appreciable diffusion of radicals, either because they possess kinetic energy or because of local heating, then irradiation at a lower temperature should produce clusters occupying a smaller volume with correspondingly higher local concentrations. The few measurements I have made so far at $4.2 \% \mathrm{~K}$ are inconclusive, but it does appear that irradiation by electrons at $4.2^{\circ} \mathrm{K}$ followed by measurement at $77^{\circ} \mathrm{K}$ produces exactly the same spectrum as irradiation and measurement both at $77^{\circ} \mathrm{K}$. Hence the observed local concentrations may be very close to the initial ones at the moment of formation. Whether or not a $100-e V$ cluster should occupy the same volume in frozen solutions of hydrogen peroxide as in liquid water, I don't know. 
It is also possible to obtain some information about the volume occupied by a cluster from the buildup of radical concentration with dose. If it is assumed that a given amount of absorbed energy affects a certain restricted volume, then the total volume affected increases with dose, following an exponential curve. The observed buildup of radicals (Fig. 1) follows a curve which is approximately exponential; from this one can calculate a minimum value for the volume affected by the energy packet. For frozen solutions of hydrogen peroxide this calculation gives a minimum value equal to a sphere of $35 \AA$ diameter for a $100-\mathrm{eV}$ cluster. The previous discussion siggests that the volume is considerably larger than this; however, even this minimum value is larger than the value often assumed in the radiation chemistry of water.

This study is in part performed under contracts with the National Aeronautics and Space Administration.

\section{$\underline{\text { References }}$}

1. R. Livingston, Radiation Research Supplement 1, 463 (1959).

2. S. J. Wyard, Proceedings of the XIth Coloque Ampere, 388 (1962).

3. R. C. Smith and S. J. Wyard, Nature 191, 897 (1961).

4. A. H. Samuel and J. L. Magee, J. Chem. Phys. 21, 1080 (1953); the size of the spur was chosen so as to obtain agreement with experimental results.

5. P. J. Dyne and J. M. Kennedy, Can. J. Chem. 36, 1518 (1958); these authors point out that the model agrees with experiment only if the diameter of a typical spur is less than $40 \AA$. 


\title{
EPR STUDIES ON OH RADICAL IDENTIEICAITION_IN_LRRADIATED $\mathrm{H}_{2} \mathrm{O}$
}

\author{
T. E. Gunter ${ }^{*}$ and C. D. Jeffries ${ }^{\dagger}$
}

After the identification of atomic hydrogen in irradiated acids at $77^{\circ} \mathrm{K}$ by Livingston et al. ${ }^{1}$ and in neutral ice at $4.2^{\circ} \mathrm{K}$ by: Piette et al. 2 it became popular to attribute the rather poorly resolved EPR spectrum in irradiated polycrystalline ice at $77^{\circ} \mathrm{K}$, and sometimes that of ice irradiated at $4.2^{\circ} \mathrm{K}$, to the OH radical. This was a good guess as to the identity of the radical species in the cases mentioned above, but real proof that the $\mathrm{OH}$ radical is formed when $\mathrm{H}_{2} \mathrm{O}$ is irradiated was not provided by the experiments with polycrystalline ice.

The first contribution of the present study to this field came when single crystals of ice irradiated at $77^{\circ} \mathrm{K}$ were studied in detail by EPR at both $77^{\circ} \mathrm{K}$ and $4.2^{\circ} \mathrm{K}$. In these studies ä effective spin Hamiltonian was sought which took account of Zeeman and hyperfine interactions. Figure 1 shows, as an example of these spectra, the spectra measured at both $77^{\circ} \mathrm{K}$ and at $4.2^{\circ} \mathrm{K}$ of a single crystal of ice irradiated at $77^{\circ} \mathrm{K}$, both spectra taken at the same orientation in the plane of hexagonal symmetry.

Whereas in past work quite different spectra were found for polycrystalline ice irradiated and studied at $77^{\circ} \mathrm{K}$ and ice irradiated and studied at $4.2^{\circ} \mathrm{K}$ (each spectrum similar to its single.-crystal courterpart shown in Fig. 1), it was usually as sumed that only one of them could be the $\mathrm{OH}$ radical. The study presented here showed that the form of the spectrum of ir radiated ice goes reversibly (without change) between the previously published $4.2^{\circ} \mathrm{K}$ and $77^{\circ} \mathrm{K}$ spectral forms. Hence it is likely that the spectra are caused by the same type of radicals. The reason for this spectral change does not appear to be a simple phase change, for both spectra showed hexagonal symmetry, as expected from tetrahedrally bonded ice. Also the spectra of crystals which had been irradiated at $77^{\circ} \mathrm{K}$, cooled to $4.2^{\circ} \mathrm{K}$, and later heated again to $77^{\circ} \mathrm{K}$ were of the single-crystal type; rather than the polycrystalline type. As well as could be determined, these spectra were identical to those of the same crystal taken after irradiation at $77^{\circ} \mathrm{K}$ but prior to cooling to $4.2^{\circ} \mathrm{K}$.

The reason why the irradiated ice spectrum changes with temperature is still being studied; it is believed to be related to the splitting and populations of levels affected by crystal-field (hydrogen bond) interaction. Because there are many inequivalent sites in the ice lattice occupied by the radicals (seven, presumably, for $\mathrm{OH}$ ), and because of the large number of protons surrounding each site and producing line broadening, it was found impossible to completely resolve the spectrum for the radicals formed in irradiated single-crystal ice.

\footnotetext{
*NSF Predoctoral Fellow, Donner Laboratory.

${ }^{\dagger}$ Physics Department, University of California.
} 


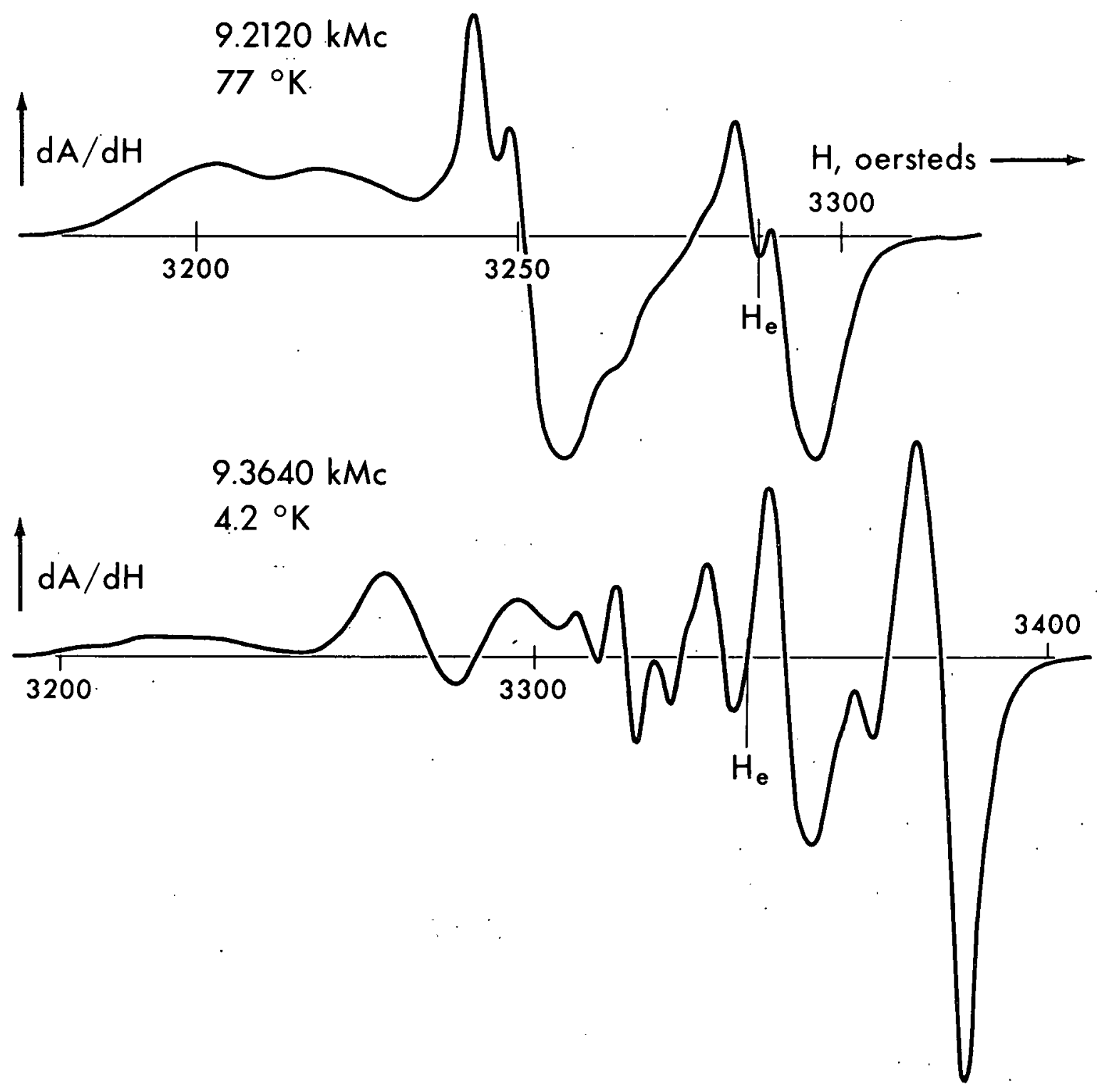

$M \cup B \cdot 3.672$

Fig. 1. Spectra of single-crystal ice irradiated by electrons at $77^{\circ} \mathrm{K}$ and measured at $77^{\circ} \mathrm{K}$ and at $4.2^{\circ} \mathrm{K}$. 
Irradiated $\mathrm{H}_{2} \mathrm{O}$ was next studied in the form of water of crystallization in $\mathrm{CaSO}_{4} \cdot 2 \mathrm{H}_{2} \mathrm{O}$. In this crystal the water occupies only two inequivalent sites, and the proton density is much less than in ice itself. The spectra of irradiated $\mathrm{CaSO}_{4} \cdot 2 \mathrm{H}_{2} \mathrm{O}$ observed at $77^{\circ} \mathrm{K}$ show an anisotropic hyperfine doublet with two inequivalent sites and a weak isotropic line near the freeelectron $g$ factor. This is similar in appearance (though not in scale) to the spectra observed by Wigen and Cowen, 3 who used somewhat different ir radiation procedures. We seek to identify the hyperfine doublet with the $\mathrm{OH}$ radical, and to observe that the isotropic spectrum is similar to that of the trapped electron seen by Henriksen. 4

An example of the observed spectra of irradiated $\mathrm{CaSO}_{4} \cdot 2 \mathrm{H}_{2} \mathrm{O}$ is found in Fig. 2 . This spectrum was made with the dc magnet field almost perpendicular to the symmetry axis of the radical. In this orientation the two inequivalent sites give the same spectrum.

The observations for irradiated $\mathrm{CaSO}_{4} \cdot 2 \mathrm{H}_{2} \mathrm{O}$ were fitted to a spin Hamiltonian of the form

$$
\mathcal{H}=\beta \vec{S} \cdot\left(\begin{array}{lll}
g_{\perp} & 0 & 0 \\
0 & g_{\perp} & 0 \\
0 & 0 & g_{\|}
\end{array}\right) \cdot \vec{H}+\vec{S} \cdot\left(\begin{array}{ccc}
B & 0 & 0 \\
0 & B & 0 \\
0 & 0 & A
\end{array}\right) \vec{I} \text {, }
$$

where $\beta$ is the Bohr magnetron, $H \cdot$ the magnetic field intensity, $\vec{S}$ the electron spin, and $\vec{I}$ the nuclear spin. $(S=1 / 2, I=1 / 2)$. Values for $\cdot g_{1}$, $g_{\| l}, A$, and B are given, along with a comparison of the data to the predicted line positions of the chosen spin Hamiltonian, on Fig. 3.

The effective spin Hamiltonian found for the anisotropic lines given by irradiated $\mathrm{CaSO}_{4} \cdot 2 \mathrm{H}_{2} \mathrm{O}$ represents a paramagnetic species with nuclear spin 1/2, effective electron spin 1/2 (as would be expected from a quenched $\mathrm{OH}$ radical spectrum), and axial symmetry. $\mathrm{OH}$ is the only candidate radical species which meets all the requirements, for $\mathrm{O}_{2} \mathrm{H}$ would not be expected to show axial symmetry for Zeeman and hyperfine interactions. The lack of axial symmetry in $\mathrm{O}_{2} \mathrm{H}$ could be somehow masked by trapping interactions, however, so one cannot completely exclude it when identifying the source of the hyperfine doublet.

We qualitatively explain the relative $g$ anisotropy and quenching in the above-mentioned samples as follows: For $\mathrm{OH}$ radical one wo uld expect orders of interaction somewhat like those of the iron group of paramagnetic elements. That is, strong molecular or atomic forces "lock" the molecule or atom in place and lead to nonconservation of angular momentum. That means that $L$ is not a good quantum number and the $L$ part of the spin Hamiltonian is quenched. In ice the "locking" mechanism is a strong hydrogen bond and the quenching is essentially complete $(\Delta \mathrm{g} / \mathrm{g}$ cannot be greater than $0.5 \%$ ). . In $\mathrm{CaSO}_{4} \cdot 2 \mathrm{H}_{2} \mathrm{O}$, on the other hand, the "locking" mechanism is.crystalline fields and is relatively weaker. The quenching is consequently not complete (here $\Delta \mathrm{g} / \mathrm{g}=5.1 \%$ ).

It may be possible after more study to explain the spectra of irradiated single-crystal ice by setting up a spin Hamiltonian with a hyperfine interaction similar to that found in irradiated $\mathrm{CaSO}_{4} \cdot 2 \mathrm{H}_{2} \mathrm{O}$ with a Zeeman interaction giving less $g$ anisotropy. 


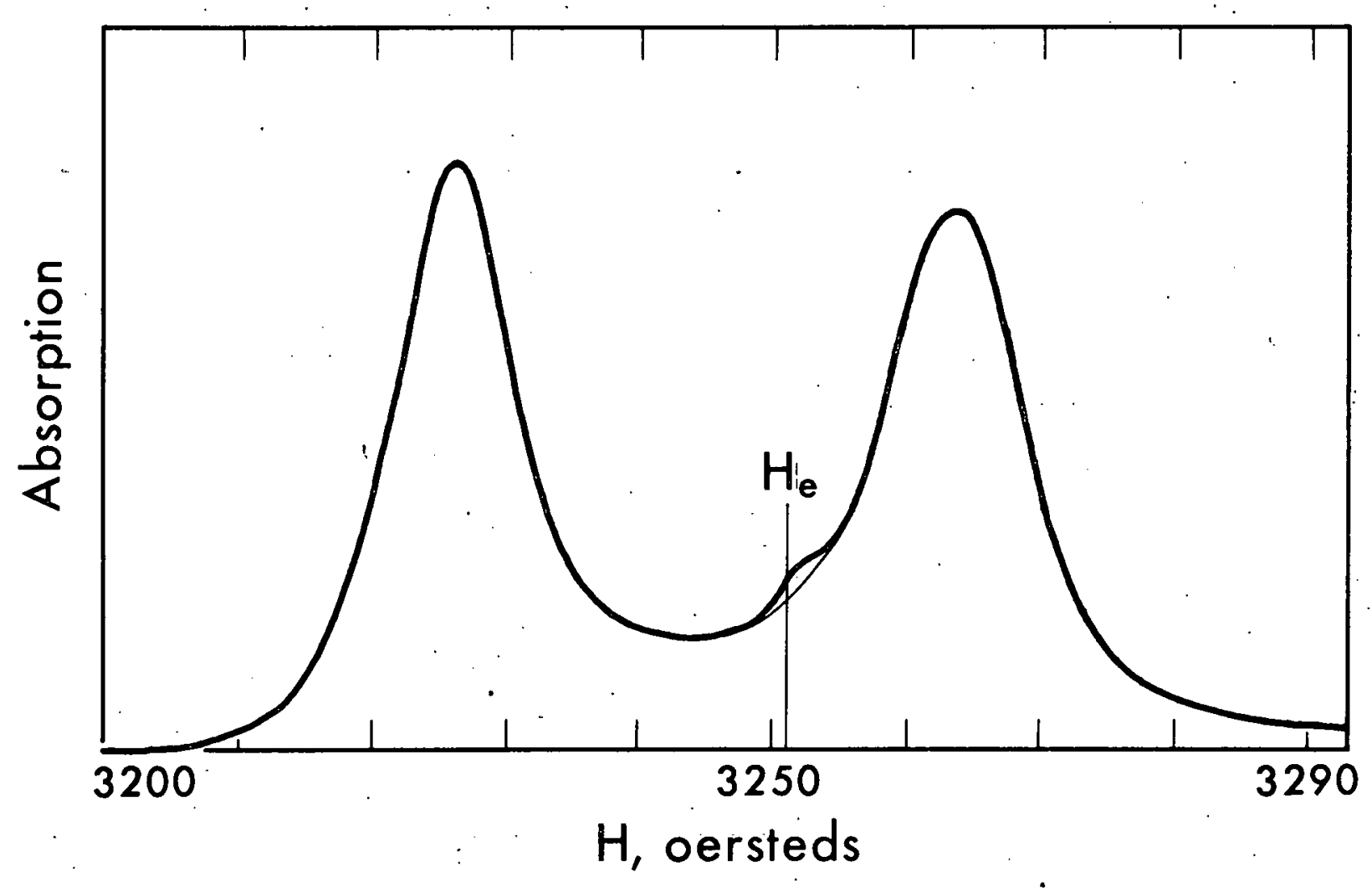

MU B - 3671

Fig. 2. Spectrum of $\mathrm{CaSO}_{4} \cdot 2 \mathrm{H}_{2} \mathrm{O}$ irradiated by electrons at $77^{\circ} \mathrm{K} . \quad \mathrm{H} \|$ [010]; $9.1110 \mathrm{kMc}$. 


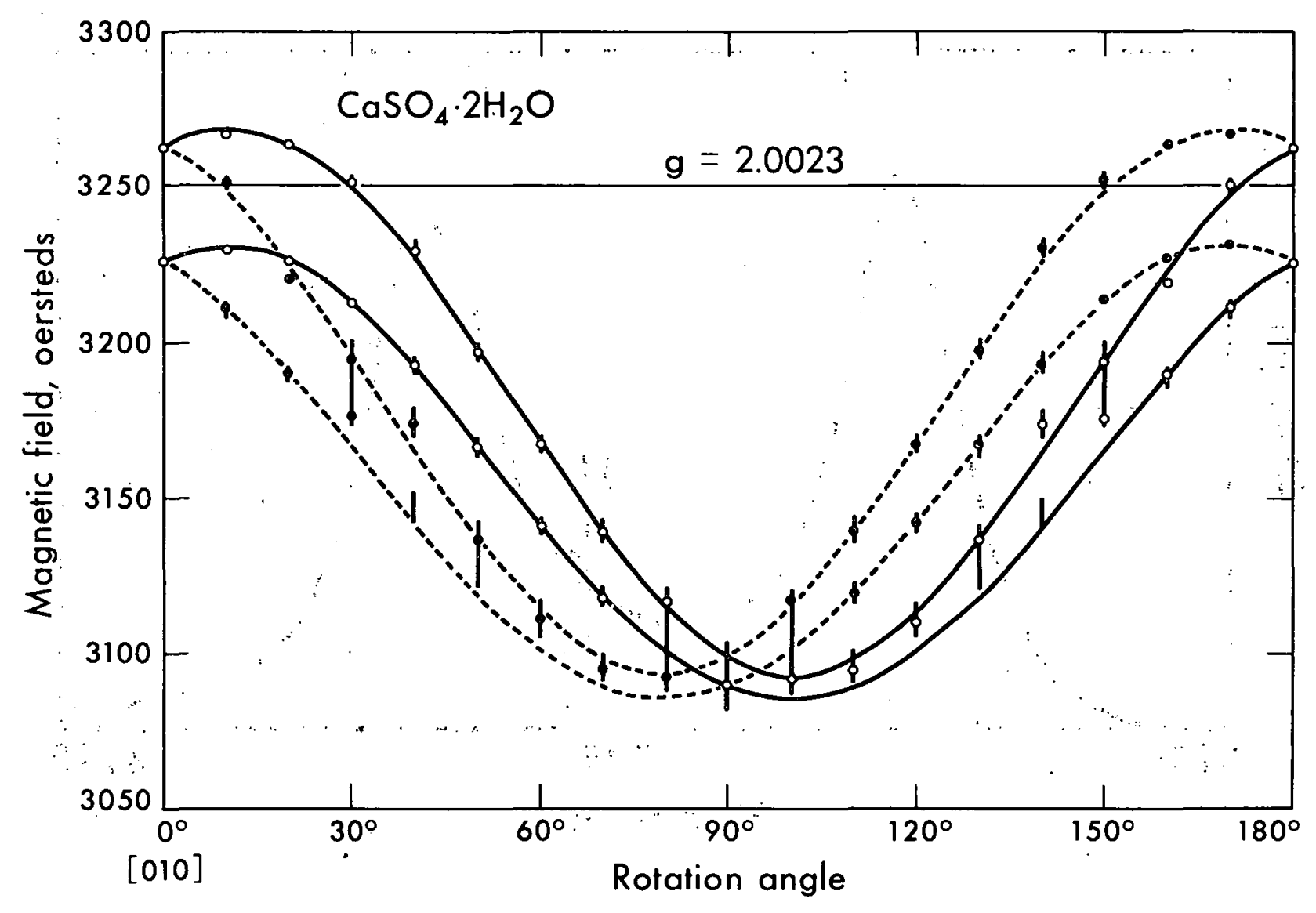

$M \cup B-3670$

Fig. 3. Spin Hamiltonian for irradiated $\mathrm{CaSO}_{4} \cdot 2 \mathrm{H}_{2} \mathrm{O}$. $\mathrm{g}_{\|}=2.1108, \mathrm{~g}_{1}=2.0028 ; \mathrm{A}=33.3 . \mathrm{Oe}, \mathrm{B}^{4}=37.9 \mathrm{Oe}$. 
Presently work either in progress or planned includes:

(a) attempting to see atomic hydrogen spectra from the $\mathrm{H}$ atom in $\mathrm{CaSO}_{4} \cdot 2 \mathrm{H}_{2} \mathrm{O}$ samples irradiated and observed at $4.2^{\circ} \mathrm{K}$,

(b) studying the spectra of other simple hydrated crystals after irradiation, in which either $\mathrm{Ca}^{++}$or $\mathrm{SO}_{4}{ }^{--}$or both are replaced by other ions.

This study was supported in part by the National Aeronautics and Space Administration.

\section{References}

1. R. Livingston, H. Zeldes, and E. Taylor, Disc. Faraday Soc., 19, 166 (1956).

2. L. Piette, R. Rempel, H. Weaver, and J. Flournoy, J. Chem. Phys. 30, 1623 (1959).

3. P. E. Wigen and J. A. Gowen, J. Chem. Phys. Solids 17, 26 (1960).

4. T. Henriksen, to be published. 


\section{ELEGTRONMICROSCOPY OF SINGLE-STRANDED DNA: CIRCULARIT'Y O'F $\phi \mathrm{X}-174$ DNA}

David Freifelder, ${ }^{*}$ Albrecht K. Kleinschmidt; ${ }^{\dagger}$ and Robert L. Sinsheimer ${ }^{\dagger}$

The DNA of coliphage $\phi X-174$ is single-stranded ${ }^{1}$ and apparcntly also circular. This latter point, which is based upon the resistance of the DNA to digestion by exonucleases, is confirmed in this paper by electron microscopy.

Direct observation of DNA molecules by electron microscopy is pos sible if the DNA is adsorbed onto protein monolayers. 3 However, this has been complicated by entangling of a variable fraction of the molecules, although it is usually possible to find a sufficient number of extended, untangled filaments: that a length distribution can be obtained.

When $\phi X-174$ DNA was examined, exceedingly severe tangling obviated any possible conclusion concerning length or configuration, although the success with the double-stranded replicating form ${ }^{4}-$ i. $_{\text {. }}$, the clear demonstration of ring molecules 5,6 - - strengthened the original surmise.

We have assumed that intramolecular hydrogen bonding is principally responsible for this problem and have therefore modified the preparation procedure to avoid it. This modification consists simply of denaturating the DNA by one of the methods of Freifelder and Davison ${ }^{7,8}$ in order to break all hydrogen bonds, and subsequently handling the DNA in the presence of concentrations of formaldehyde which prevent hydrogen bond reformation.

DNA of $\phi X-174$ was prepared according to the method of Sinsheimer ${ }^{1}$ and adjusted to a concentration of $70 \mu \mathrm{g} / \mathrm{ml}$ in $0.1 \mathrm{M} \mathrm{NaCl}-0.05 \mathrm{M}$ Tris, $\mathrm{pH} 7.7$, to serve as a stock. The solution for spreading was made by mixing the following components in sequence for the indicated standing times: $0.04 \mathrm{ml} \mathrm{DNA}+0.04 \mathrm{ml} 1 \mathrm{M} \mathrm{NaOH}, 20 \mathrm{sec} ; 0.4 \mathrm{ml} 37 \% \mathrm{HCHO}$ (adjusted to pH 11 with $1 \mathrm{~N} \mathrm{NaOH}), 3 \overline{0}$ sec; $0.1 \mathrm{ml} 1 \mathrm{M} \mathrm{KH}_{2} \mathrm{PO}_{4} ; 0.6 \mathrm{ml} 0.01 \mathrm{M} \mathrm{PO}_{4}^{-}$ $0.005 \mathrm{M}$ versēne, $\mathrm{pH} 7.8 ; 0.4 \mathrm{ml} 4 \mathrm{M} \mathrm{NaCl}$. One-tenth $\mathrm{ml}$ of the denatured DNA solution was diluted to $0.5 \mu \mathrm{g} / \overline{\mathrm{m}}$ by addition of $1 \mathrm{M} \mathrm{NH}_{4}$ acetate containing $0.5 \% \mathrm{HCHO}$ (neutralized and boiled for 10 minutes). Finally, $0.1 \mathrm{ml}$ of $0.01 \%$ cytochrome $\mathrm{C}$ in $1 \mathrm{M} \mathrm{NH}_{4} \mathrm{Ac}$ was added. This solution was spread 4 min later by the standard method, 3 except that the spreading was done on $0.5 \% \mathrm{HCHO}$ (pretreated as above) instead of water. Lower concentrations of HCHO were not satisfactory. The visco-elastic properties and the spreading speed of the film on this solvent are comparable to those obtained with spreading on water. The film was transferred to carbonized support films on Pt grids by touching the surface, and the adhering droplet was removed by touching an ethanol surface. 5 After drying with filter paper, the preparation was rotary-shadowed with uranium at an angle of 6 to 10 degrees. Undenatured $\phi \mathrm{X}-174$ DNA was also examined by the standard technique (without alkali and $\mathrm{HCHO}$ ).

\footnotetext{
*Donner Laboratory of Biophysics and Medical Physics, University of California, Berkeley, California.

†Virus Laboratory, University of California, Berkeley, California.

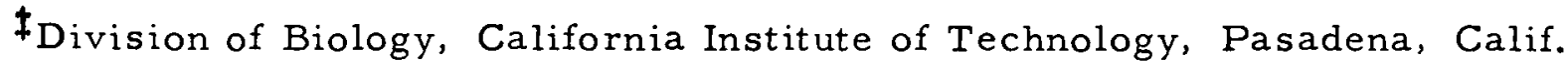


Figure 1 shows representative single-stranded rings of $\phi \mathrm{X}-174$ DNA. In a typical field about half of the DNA is easily seen as circular molecules; filaments account for fewer than $2 \%$. The remainder of the DNA consists of molecules overlapping, aggregated, or tangled, which can be substantially reduced by spreading the DNA at lower concentrations. When mixed with other double-stranded material, single strands appear thinner, are more difficult to see because of lower contrast with the background and, in general, show sharp kinks, an observation consistent with the expected greater flexibility of the single strands. Undenatured preparations (untreated with alkali and $\mathrm{HCHO}$ ) show badly tangled masses, yet without any visible free ends.

The lengths of most of the rings were measured by tracing a projected enlarged image on paper and laying 1/32-in. polyethylene tubing along the path. A histogram of the measured lengths of 186 rings is shown in Fig. 2 . The mean contour length is $1.77 \pm 0.13 \mu(7.3 \%)$, and is greater than that found for the replicating form $(1.70 \mu \pm 7 \%) .5$ The greater mean length probably reflects the greater flexibility and lesser degree of coiling of single-stranded DNA, although some effect of HCHO is clearly possible. On the basis of a molecular weight of $1.7 \times 10^{6} 1$ the mass per unit length of molecules prepared in this way is $0.95 \times 10^{6}$ daltons/micron, approximately half that found for double-stranded DNA.

The small number of filaments is an indication of the safety of the alkali treatment for denaturating DNA, 7 and furthermore reflects the stability of the linker causing ring closure. We assume that this is probably a covalent bond. This is consistent with the resistance of infectious $\phi \mathrm{X}-174$ DNA to alkali.

Further work is in progress using denatured single-stranded bacteriophage DNA derived from phages possessing double-stranded DNA. 10, 11 

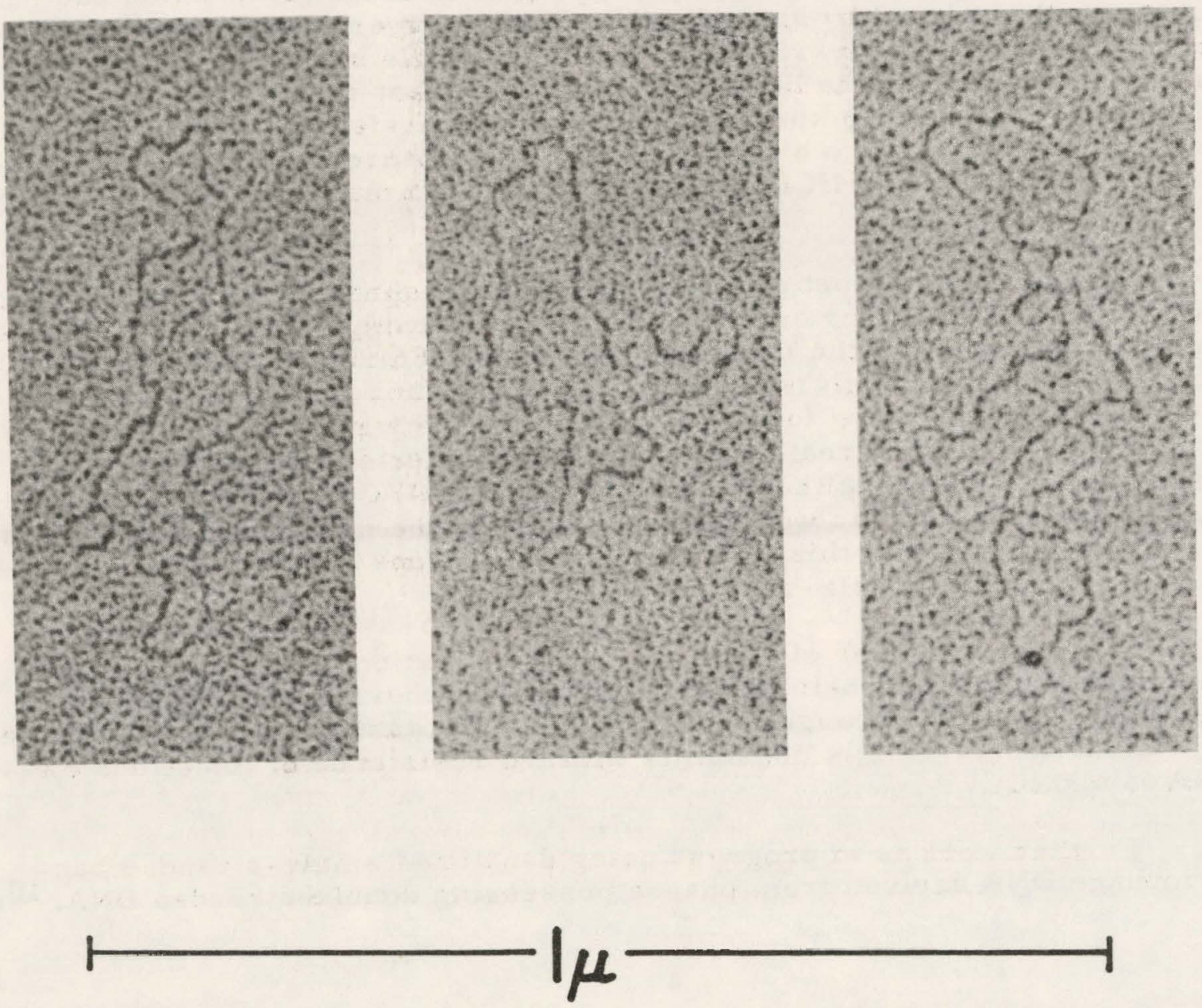

ZN-4409

Fig. 1. Electron micrographs of $\phi X-174$ DNA rings. 


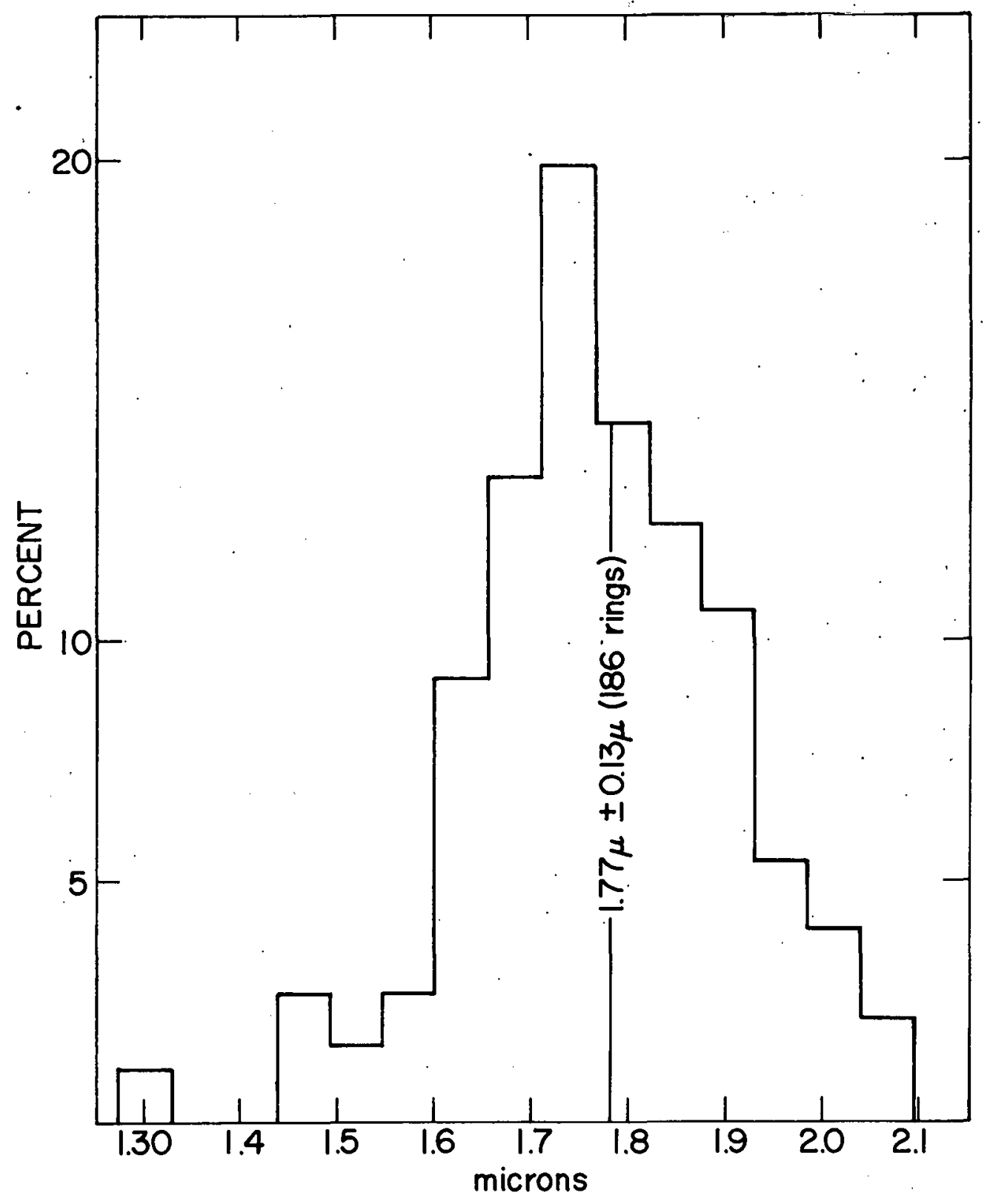

MUB -3384

Fig. 2. Histogram showing lengtn arstribution of $186 \phi \mathrm{X}-174$ DNA rings. The error shown for the mean is the standard deviation. 


\section{$\underline{\text { References }}$}

1. R. L. Sinsheimer, J. Mol. Biol. 1, 43 (1959).

2. W. Fiers and R. L. Sinsheimer, J. Mol. Biol. 5, 408 (1962).

3. A. K. Kleinschmidt and R. K. Zahn, Z. Naturforschung 1.4b, 770 (1959).

4. R. L. Sinsheimer, B. Starman, C. Nagler, and S. Guthrie, J. Mol. Biol. 4, 142 (1962).

5. A. K. Kleinschmidt, A. Burton, and R. L. Sinsheimer, Science 142, 961 (1963).

6. B. Chandler, M. Hayashi, M. N. Hayashi, and S. Spiegelman, Science 143, 47 (1964). . :

7. D. Freifelder and P. F. Davison, Biophys. J. 3, 49 (1963).

8. P. F. Davison, D. Freifelder, and B. W. Holloway, J. Mol.: Biol. 8 , 1 (1964).

9. R. L. Sinsheimer, unpublished.

10. This work was supported in part by grants from the Atomic Energy Commission and the National Aeronautics and Space Administration, and by grants No. AI01267 from the National Institute of Allergy and Infectious Disease, and No. CA02245 from the National Cancer Institute.

11. We gratefully acknowledge the help of Susan G. Johnson, who took the electron micrographs, and Katherine Le Blanc, Kristin Chung, and John Polacheck, who traced and measured lengths. 


\section{INACTIVATION AND REGOVERY OF MICROORGANISMS AFTER TREATMENT WITH ULIRAVIOLET LIGHT OR OTHER MUTAGENS ${ }^{*}$}

Robert H. Haynest

It is my purpose in this essay to sketch in rather broad outline a picture of those macromolecular events that appear to be crucial to the inactivation of bacteria by ult raviolet light (uv). Since the concepts involved are applicable to cell killing by other mutagens 8 uch as $x$ rays and the radiomimetic alkylating agent, nitrogen mustard (HN2), frequent comparisons will be made to the actions of these agents, and consideration will also be given to the biological interactions that occur among them. Although I have necessarily been quite parochial in the actual presentation of data, most of which come from my laboratory in Chicago, still, my primary concern has been to discuss general ideas rather than review all the possibly relevant literature. These restrictions have made my task the more embarrassingly difficult, since the compelling biochemical justification for the hypotheses with which my experiments are merely consistent is largely the work of others, and is to be found especially in the elegant experiments by Richard Setlow and his associates at Oak Ridge. (For reviews and background material relevant to this article see references 1-7 and the related papers in this Symposium).

The Observation of Photoinactivation

Cell killing, or reproductive death, is the most prominent and most likely effect resulting from the exposure of bacteria to relatively low incident doses of $2537-\AA$ ultraviolet light. Operationally, it is defined as failure of the irradiated bacteria to multiply and form visible colonies (clones) upon incubation on some suitable growth medium. The shape of the dose-effect curves for uv inactivation (and also for $x$-ray and HN2 inactivation) is known to depend on many details of the growth, irradiation, and assay procedures employed. $8-11$ Thus, it is convenient to first consider data obtained under some set of "standard" experimental conditions, and subsequently to try to account for the effects of such modifying factors.

In the experiments described in this paper, the conditions adopted as standard for the determination of bacterial survival curves were as follows:

The experimental work reported herein was supported at the University of Chicago by a grant from the National Institutes of Health, U. S. Public Health Service (GM-10877); further support for this research was provided at the University of California by the U. S. Atomic Energy Commission.

†Presented at the NAS-NRC Symposium on Molecular Mechanisms in Photobiology, Wakulla Springs, Florida, February 1964; to appear in Photochemistry and Photobiology, 1964.

\$New permanent address: Donner Laboratory of Biophysics and Medical Physics, University of California, Berkeley, California. 
the bacteria (mostly strains of $\mathrm{E}$. coli) were grown at their optimal temperature from a small inoculum in a buffered, aerated, complete liquid medium (such as Difco Peptone or Brain-Heart Infusion); the cells were harvested in the stationary phase after 18 to 20 hours of growth, washed, and resuspended $\left(10^{6}\right.$ to $\left.10^{8} \mathrm{cells} / \mathrm{ml}\right)$, for irradiation or other experimental treatment in phosphate buffer or distilled water at room temperature; samples of the irradiated suspensions were then plated on Difco Nutrient Agar in order to determine the fraction of cells capable of giving rise to visible colonies after 24 hours' incubation at $37^{\circ} \mathrm{C}$.

The experimental features most worthy of note are that the cells were irradiated in stationary phase in a nonnutritive suspension, well below their optimal growth temperature, and then stimulated to multiply by exposure to a complete growth medium. Thus, the fast physicochemical reactions which give rise to the initial photoproducts take place under conditions of minimum metabolic activity, whereas the biochemical events crucial to survival occur slowly during the first few hours after plating. Clearly, the main problem for photobiologists is to determine how these essential biosynthetic reactions are affected by the presence of whatever stable photoproducts have been formed. It is meaningless to ask whether a cell is "alive" or "dead" immediately after irradiation, since operationally, its viability can only be determined by the final outcome of an arbitrary plating assay; and during the lengthy period of growth "lag" that intervenes between the cessation of irradiation and the onset of multiplication, there is ample time for the operation of certain enzymatic processes which can serve to suppress or modify the expression of the initial radiation damage.

It must be recognized that the interpretation of these experiments is complicated by the fact that the physiological state of cells harvested from stationary broth cultures is not well-defined, and that such populations are heterogeneous with respect to macromolecular composition (e: g., number of nuclei, DNA/protein ratio, etc.), and the time required to attain balanced growth after plating. 12,13 This situation could be improved by using synchronously dividing cultures, 14 or even log-phase cells grown in a minimal medium. However, the inferences drawn from the data presented.below are not substantially compromised by these biological uncertainties. None of the survival curves have resistant "tails" or upward concavities which would arise from relevant population heterogeneities; and the characteristic fluctuations in photosensitivity that have been observed during the growth (in broth or minimal media) of either synchronized ${ }^{15}$ or mass cultures 11 of E. coli are not large, and appear primarily as variations in the shoulder, rather than the limiting slope, of the survival curves.

The Concept of Target Macromolecules Relevant to Inactivation

Much of radiobiological thought has been influenced by the idea that cells contain certain nonredundant "targets" or "sensitive sites, "which. might be anything from molecules to organelles but whosc structural integrity is essential for survival. 16 Damage to an appropriate number of these targets, whether induced by radiation or other agents, is assumed to be lethal, whereas damage produced in other cell components is regarded as irrelevant to inactivation. Although formal target theory provides some useful empirical equations for fitting radiation dose-effect curves, such 
exercises are of little heuristic value in advancing our understanding of photoinactivation. However, the problem is still most usefully formulated by assuming the existence of a class of target macromolecules relevant to inactivation, and then inquiring as to their identity, the chemical nature of the changes produced in them by the radiation, and the biochemical consequences of these changes.

At first sight, the number and complexity of the photochemical reactions that can take place in cells exposed to uv seems sufficient to confound any attempt to elucidate the mechanisms of photoinactivation. And furthermore, since it is possible that inhibition of colony formation can arise in several different ways, it might appear whimsical to focus one' $s$ attention on any one mode of death. However, in view of the crucial role of DNA in cell growth and division, and the strong uv absorption of the organic bases in nucleic acids, some simplification becomes possible. Two important ideas form the basis of current speculation: (a) uv photoproducts in DNA constitute macromolecular structural defects, which, unless repaired, have a finite probability of giving rise to some biosynthetic failure, such as inhibition of DNA synthesis, or an error in protein synthesis, which leads to cell death; and (b) there are enzyme systems which, under suitable conditions, can serve to repair, eliminate, or bypass certain kinds of structural damage in DNA. Thus, survival is determined by the net probability that radiation-induced structural defects in DNA either persist and prove lethal, or are eliminated through the action of some enzymatic "reactivation" mechanism before the onset of growth on the plates.

This picture enlarges on the traditional target-theoretical description of cell killing in two subtle, but important ways: First, it emphasizes the indeterminancy of death during the immediate postirradiation "repair" period up to the time that failure of clone formation can actually be observed. And secondly, killing is not viewed as the inevitable outcome of the accumulation of any given number of physical hits in sensitive sites, since a substantial fraction of the molecular changes initially produced during irradiation might be subsequently repaired.

In target theory, shoulders on survival curves reflect the departure from a strictly discontinuous threshold response that would arise from statistical fluctuations in the number of physical hits to be found among the cells of an irradiated population at any given level of dose; whereas here, shoulders are to be regarded primarily as a manifestation of the failure of a reactivation mechanism with increasing dose. ${ }^{7}$ (This is not to imply that survival curve shoulders cannot also be due to target multiplicity, since Norman has shown 17 that the extrapolated target numbers for uv inactivation of Neurospora conidia can be precisely correlated with the average number of nuclei per conidium).

Since this scheme is based on the assumption that survival after ir radiation is determined by the relative probabilities of inactivating and reactivating events, clearly, it is sufficiently general a priori to account for virtually any experimental modification of photosensitivity that might be observed: that is, any apparent increase in sensitivity could be attributed to a suitable combination of increased initial damage or the inhibition of = reactivation or both; and vice versa for any apparent decrease in sensitivity. 
Therefore, if this picture is to have any predictive value, evidence must be presented, first, to justify the identification of DNA as the most prominent target relevant to photoinactivation, and secondly, to support the idea that uv photoproducts in DNA can be repaired in vivo.

Evidence Implicating DNA as a Target Relevant to Cellular Inactivation

The hypothesis that DNA is the most important macromolecular target, not only for uv, but also for $\mathrm{x}$-ray and HN2 inactivation, is supported, in the most general way, by the fact that all three are mutagenic agents, $2,5,18,19$ by their common ability to produce chromosome abberations, 20, 21 by the influence of ploidy on cellular sensitivity, $22-24$ and by the large ratio of nuclear to cytoplasmic sensitivity observed for a variety of effects in partial cell and microbeam irradiation experiments. 25-29 Uniquely for uv, an historically important observation was the congruence of the action spectrum for the inactivation of various bacteria with the absorption spectrum of nucleic acids; $30-33$ and similar action spectra have been obtained for mutations in fungi, 33 mosaicism in maize endosperm, 34 and chromosomal abberations in Tradescantia. 35 Although this indirect evidence is quite comforting, it must be emphasized that many of these effects are at best only remotely related to cellular inactivation, and that the possible importance of damage to protein or to nucleolar or cytoplasmic RNA cannot be rigorously ruled out, even in those cases in which a nucleic acid action spectrum has been observed. $27,36-38$ Also, the situation for ionizing radiation is more controversial than for uv. Alper ${ }^{39}$ has postulated the existence of non-DNA targets for a substantial fraction of the oxygen dependent component of x-ray damage; however, this should not be taken to imply that the products arising from the reaction of oxygen with radiationinduced radicals in DNA are irrelevant to inactivation. 40

The most compelling evidence implicating DNA itself as a target for both uv and $\mathrm{x}$-ray inactivation is to be found in recent work on the sensitization produced by the incorporation of base analogs into DNA. 41 In 1957, Greer and Zamenhof reported 42 that the uv sensitivity of $E$. coli could be enhanced by the incorporation of 5-bromouracil (5-BU), a halogenated analog of thymine. Since then, both uv and $x$-ray sensitization by several halogenated pyrimidine analogs, and also purine analogs such as thioguanine, 43 have been studied in considerable detail, not only in bacteria, $4-47$ but also in mammalian cells, 48-50 bacteriophages, 51-55 and transforming DNA; 56,57 and Szybalski and Lorkiewicz have shown 57 that the increase in $x$-ray sensitivity of $B$. subtilis produced by incorporated 5-BU is paralleled almost exactly by a corresponding increase in sensitivity of the transforming DNA extracted from the same cultures. On the other hand, no sensitization is observed in $E$. coli grown in the presence of 5 -fluorouracil, which --

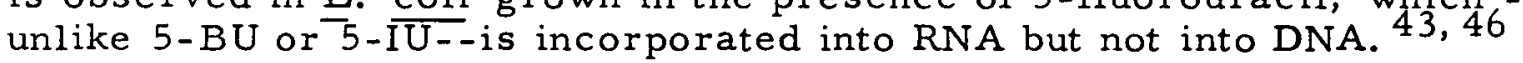

In terms of the concepts outlined above, such uv sensitization could be accounted for either on the basis of enhanced killing or impaired reactivating processes associated with 5-BU-substituted DNA, or both. In principle, the former could be due to increased energy absorption (but this is ruled out since the extinction coefficient of 5-BU is actually less than that of thymine at $2600 \AA$ ), the greater photochemical lability of 5-BU than of thymine in DNA, 58 or the formation of some new, highly toxic product. However, 
current speculation favors a failure of reactivation, $53-55$ which could arise in several possible ways, e.g., certain 5-BU photoproducts might be inherently nonrepairable; the prolific yield of photoproducts in 5-BU DNA 58 might surpass the capacity of the system for repair by binding all the available enzyme; ${ }^{54}$ or the enzyme might be unable to bind to potentially repairable, non-BU defects because of steric alterations in the secondary structure of DNA caused by neighboring 5-BU residues or their photoproducts in the polynucleotide chain. This last possibility implies that the repair enzymes are not specific for the 5-BU photoproducts themselves and is consistent with the fact that 5-BU also sensitizes to $x$ rays, and that both uv and $x$-ray sensitization can be achieved by other base analog substitutions, 43 as well as by other agents, such as HN2, 24 ethyl methane sulphonate (EMS), 59 and acriflavine, 60 all of which produce structural alterations in DNA.

Identification of DNA Structural Defects Relevant to Inactivation

Although the chemistry of uv, $x-r a y$, and HN2 attack on DNA has been extensively investigated and many reaction products and secondary structural changes identified, $5,6,61-65$ so far, only uv-induced thymine dimers have been specifically linked to cellular inactivation and reactivation in vivo. 66 Thymine dimers were first identified in uv-irradiated (2537 $\stackrel{\text { A }}{\text { ) frozen }}$ thymine solutions by Beukers and Berends, 67 and subsequently found in DNA extracted from irradiated bacteria. 68 Further studies have shown that in the biologically significant dose range they are formed of adjacent thymine residues in the same strand, 69 that dimerization may be reversed by shorter-wave-length radiation near $2400 \AA, 70,71$ that they are responsible for up to $70 \%$ of the biological inactivation of transforming DNA irradiated at $2800 \AA, 72$ and that the molecular basis of enzymatic photoreactivation 73 consists solely in the cleavage of thymine dimers. 74,75 DNA synthesis is inhibited by uv irradiation of $\mathrm{E}$. coli $\mathrm{B} / \mathrm{r}$, and this effect can be reversed by exposure to photoreactivating light. 76 Also, it has been shown that thymine dimers constitute a block to DNA synthesis in vitro. 77 Thus, it would appear that the thymine dimer can be regarded a $\bar{s}$ an example of a DNA structural defect which, unless repaired, is likely to inhibit cell multiplication by blocking DNA synthesis. 66

If the thymine dimerization reaction were uniquely important for photoinactivation, then, other things being equal, those organisms whose DNA is relatively rich in adenine-thymine (AT) base pairs should be more sensitive to uv than those with a low AT content; on this basis, uv sensitivity would be expected to increase approximately as the square of the AT content. Accordingly, we measured, under similar experimental conditions, the doseresponse curves for eight species of bacteria whose DNA base compositions span the known range from 28\% AT (M. lysodeikticus) to $66 \% \mathrm{AT}$ (M. pyogenes aureus). ${ }^{7}$ Survival curves for these two extreme cases and E. coli B/r $50 \% A T$ ) are shown in Fig. 1, from which it would appear that a positive correlation exists between uv sensitivity and AT content, although the apparent limiting slope of the survival curves increases at most linearly with AT content. Superficially at least, this would suggest that thymine dimers are important, but not the only uv photoproducts relevant to bacterial inactivation. This is hardly surprising in view of the contribution of cytosineassociated defects to nonphotoreactivable damage, 78 and their role in uv mutagenesis. 79 


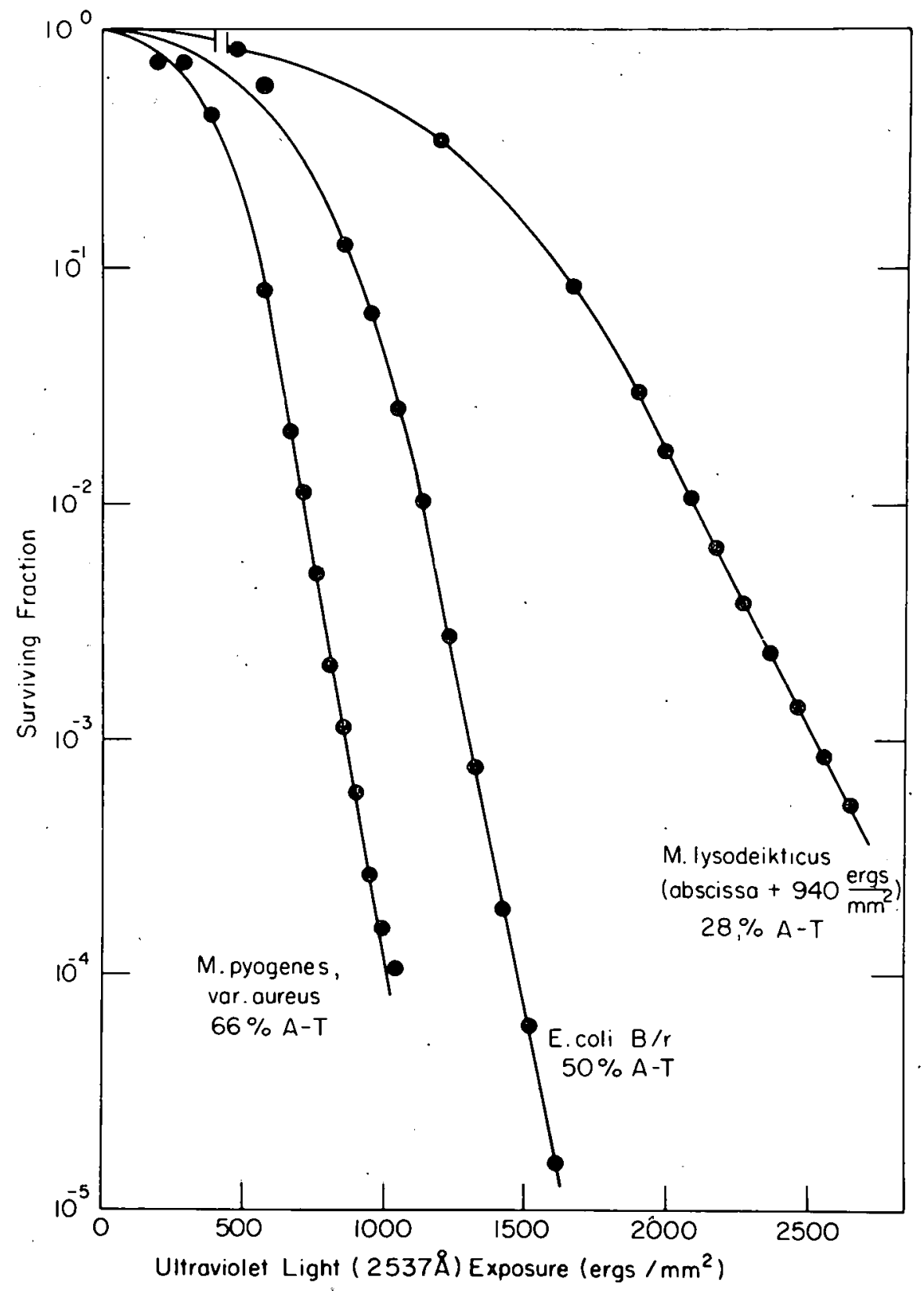

MUB-3962

Fig. 1. Survival curves for the inactivation of three species of

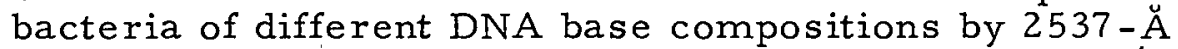
ultraviolet light. M. pyogenes aureus and E. coli $B / r$ harvested from overnight Brain-Heart Infusion (Difco) cultures, M. lysodeikticus from overnight Nutrient Broth (Difco) supplemented with $0.85 \% \mathrm{NaHCO}_{3}$; cells washed twice and resuspended for irradiation in a buffered salts solution ( $\mathrm{pH} 7.0$ ), plated on nutrient (salt) agar. DNA base compositions given as molar per cent of adeninethymine (AT). Part of the shoulder of the M. lysodeikticus curve has been deleted by displacing the abscissa $940 \mathrm{ergs} / \mathrm{mm}^{2}$ to the left. 
Similar base composition correlations have also been observed for $x-y^{80}$ and $H N 2$ inactivation (Fig. 2; Ref. 81), although for each of these agents bacterial sensitivity increascs with DNA guanine-cytosine (GC) content. The chemical basis of the $x$-ray correlation is not clear, since in aqueous solution there exist only small differences in radiochemical lability among the four bases, 61 although when they are irradiated as dry powders, only about one-fifth as much absorbed energy is required to produce a free radical (unpaired spin) in $G$ or $C$ as in $A$ or $T^{82}$ [however, this difference seems to vanish when the corresponding nucleotides are irradiated--W. Köhnlein (Yale University), personal communication]. The HN2 correlation is very likely a reflection of the fact that inter-and intrastrand cross linking of guanine residues by alkylation of their N-7 positions is the principal reaction of HN2 with DNA 64,83 . and in this case the magnitude of the correlation is more in keeping with what one would expect on the basis of the quadratic increase of $G_{p} G$ dinucleotide frequency with $G C$ content.

These correlations of bacterial sensitivity with base composition furthe $r$ support the idea that DNA is an important target for inactivation, and are consistent with chemical data on the possible localization and identity of the relevant defects. However, as will shortly become apparent, the presence and efficiency of reactivation mechanisms are such potent determinants of sensitivity to all three of these agents that it is rather surprising that such correlations can be detected at all.

Intracellular Repair of DNA Structural Defects

The existence of mechanisms capable of reducing the amount of initial radiation damage that is ultimately expressed in irradiated cells has been recognized for some time and a variety of terms have been used to describe them. 84,85 It is convenient here to distinguish among three such words which have already appeared in this paper, viz., reactivation, recovery, and repair. Reactivation is used to describe intracellular processes which serve to reduce the amount of damage expressed in cells plated immediately after irradiation without any further manipulation or treatment. Recovery is used to denote the enhancement of viability that is often observed if the plating of nonnutritive suspensions of yeast or $\mathrm{E}$. coli is delayed for some hours after irradiation. 86,87 It is possible, but yet not proven, that the recovery observed upon delayed plating is simply an extension of reactivation, however, it is helpful here to make an operational distinction between the two. Repair is used to denote the actual enzymatic steps that are involved in restoring damaged DNA molecules to a biologically functional form. [It should also be noted that reactivation and recovery occur in the dark, and are to be distinguished from photoreactivation, 73 which may be elicited upon exposure of uv-irradiated cells to visible light (blue) before plating.]

The actual reversal of potentially lethal damage can be most unequivocally demonstrated either in photoreactivation or in dark recovery phenomena, since, until recently, dark-reactivation mechanisms were more inferred than proven. In the yeast Saccharomyces cerevisiae (diploid, SC-6), a great enhancement of viability is observed if nonnutritive suspensions treated with either uv, $x$ rays, or $\mathrm{HN} 2$ are stored at $30^{\circ} \mathrm{C}$ in the dark for 6 or more hours prior to plating. 86 Maximum recovery is usually observed after 24 to 48 hours' storage, and the survival curves obtained upon delayed 


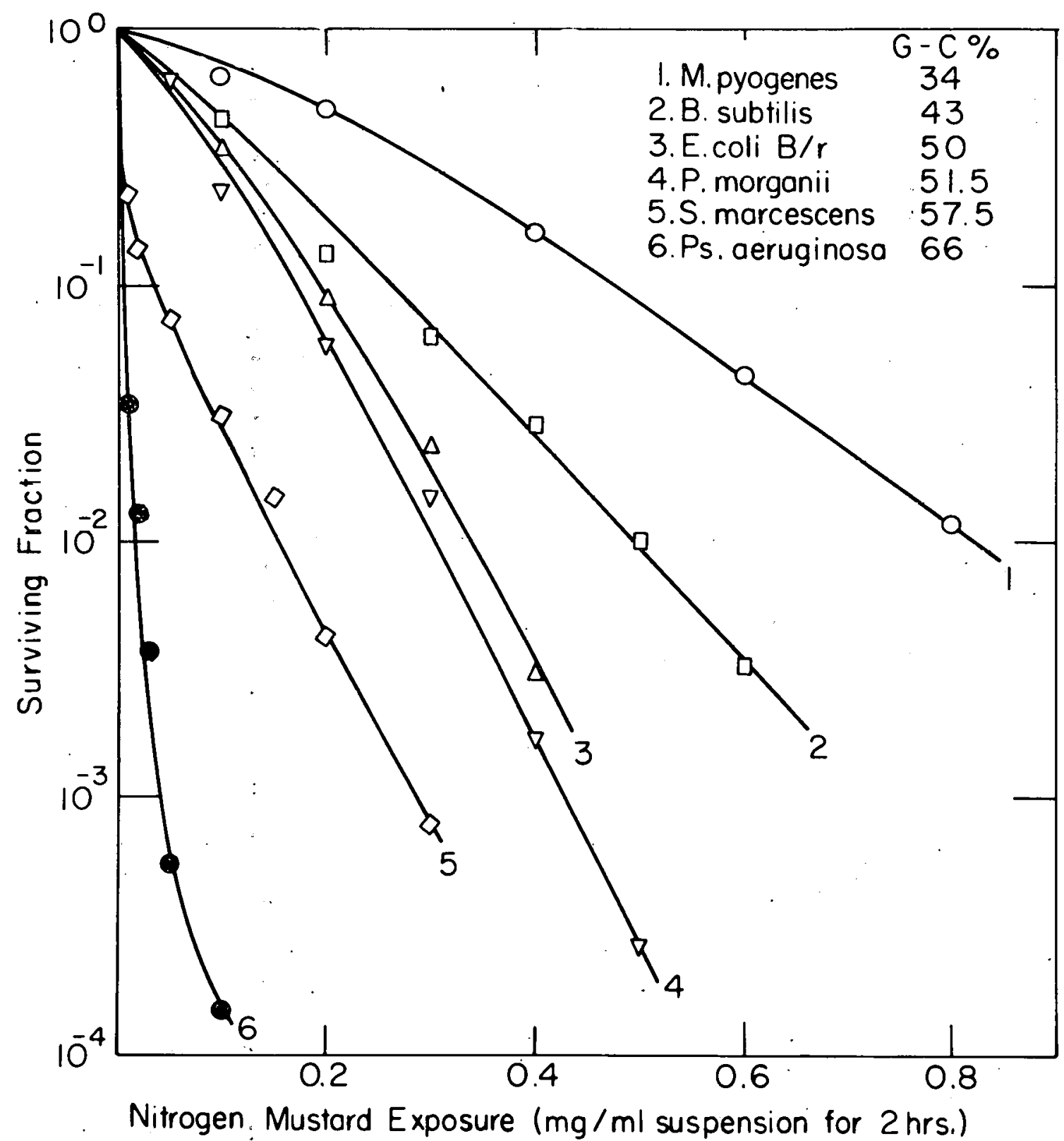

MUB-3963

Fig. 2. Survival curves for the inactivation of six species of bacteria of different DNA base compositions by the bifunctional alkylating agent, nitrogen mustard. Cells harvested from overnight Brain-Heart Infusion (Difco) cultures, washed twice and resuspended in a buffered salts solution ( $\mathrm{pH} 7.0)$. Dry, acetone recrystallized HN2 was dissolved in phosphate buffer (pH 7.0) and added immediately to the cell suspensions, which were then incubated in the presence of HN2 for 2 hours at $37^{\circ} \mathrm{C}$ before plating. DNA base compositions given as molar per cent of guanine-cytosine (GC). Note that two species of similar base compositions (E. coli $B / r$ and $P$. morganii) are equally sensitive to HN2 (curves 3 and 4). 
plating are related to those for immediate plating by a constant dosemodifying factor (Figs. 3, 4, and 5); in general, the recovery DMF is greatest for $x$ rays (2.0), intermediate for uv (1.7), and least for HN2 (1.3). No such recovery is observed for either thermal $\left(60^{\circ} \mathrm{C}\right)$ or photodynamic (acridine orange plus visible light) inactivation. Ploidies higher than diploid also recover, although haploid yeast is unique in that it is incapable of recovery after $x$ irradiation, and displays only slight recovery after uv or HN2 inactivation. The optimal external conditions for recovery are in many ways similar to those for growth, although recovery may be inhibited by the addition of minute amounts of nutrient material to the stored suspension; thus it would appear that the stimulation of growth itself is antagonistic to recovery. The process exhibits temperature and $\mathrm{pH}$ optima close to $30^{\circ} \mathrm{C}$ and $\mathrm{pH} 6.0$ respectively; it can be inhibited by the addition of trace amounts of certain cations such as copper, iron, or zinc, and also by metabolic antagonists such as 2,4-dinitrophenol, potassium cyanide, or sodium azide. Conversely, storage in an atmosphere of pure oxygen or in the presence of ATP (but not AMP) serves to enhance recovery slightly. All these observations are consistent with the idea that dark recovery in yeast is an enzymatic, energy-requiring process, capable of reducing the amount of potentially lethal damage that is expressed in cells treated with inactivating agents known to attack DNA. 59

A functionally similar reactivation process was proposed by Witkin 38 to account for the repair of those uv-induced DNA defects associated with mutation frequency decline in $E$. coli $B / x$. She suggested that this was an enzymatic, energy-requiring process that could act only before the onset 89 of DNA synthesis. Subsequently, the great uv sensitivity of $E$. coli $B{ }_{-1}$ relative to that of $\mathrm{B} / \mathrm{r}$ (Fig. 6) was attributed to the absence of just such a reactivation mechanism. 54,90 Also, the progeny of uv-sensitive $\mathrm{F}^{-}$strains of $\mathrm{E}$. coli $\mathrm{K} 12$ can be made resistant by the incorporation of a genetic locus carried on the male chromosome of uv-resistant $\mathrm{Hfr}$ strains, and it was suggested that this locus controls the formation of an enzyme capable of repairing certain uv-induced defects in DNA. 91

Recently, our understanding of the molecular basis of reactivation in E. coli $B / r$ was notably advanced by the discovery that the dark repair of $\bar{u} v$-induced thymine dimers may be initiated by the enzymatic excision of a tri- or tetranucleotide fragment from the damaged DNA strand. 92,93 It is possible that the resulting gap is enlarged by further nuclease attack and then closed by resynthesis of the excised segment. Although this final repolymerization step has not been demonstrated in vivo, a suitable reaction has been described in vitro in which the $3^{\prime}$-hydroxyIterminus of the gap would serve as a primer for the insertion of nucleotides in the sequence determined by base-pairing with the opposite intact strand. 94 [N. B.: More recently, D. Pettijohn and P. C. Hanawalt of Stanford University demonstrated a partial degradation and simultaneous synthesis of DNA in uv-irradiated E. coli TAU-bar. Their analysis showed that the newly synthesized DNA consisted of short segments along single DNA strands, and they interpreted this result as being consistent with the idea that certain uv photoproducts in DNA can be repaired by excision and repolymerization with the undamaged DNA strand serving as template (J. Mol. Biol., August, 1964).] 


\section{$-28-$}

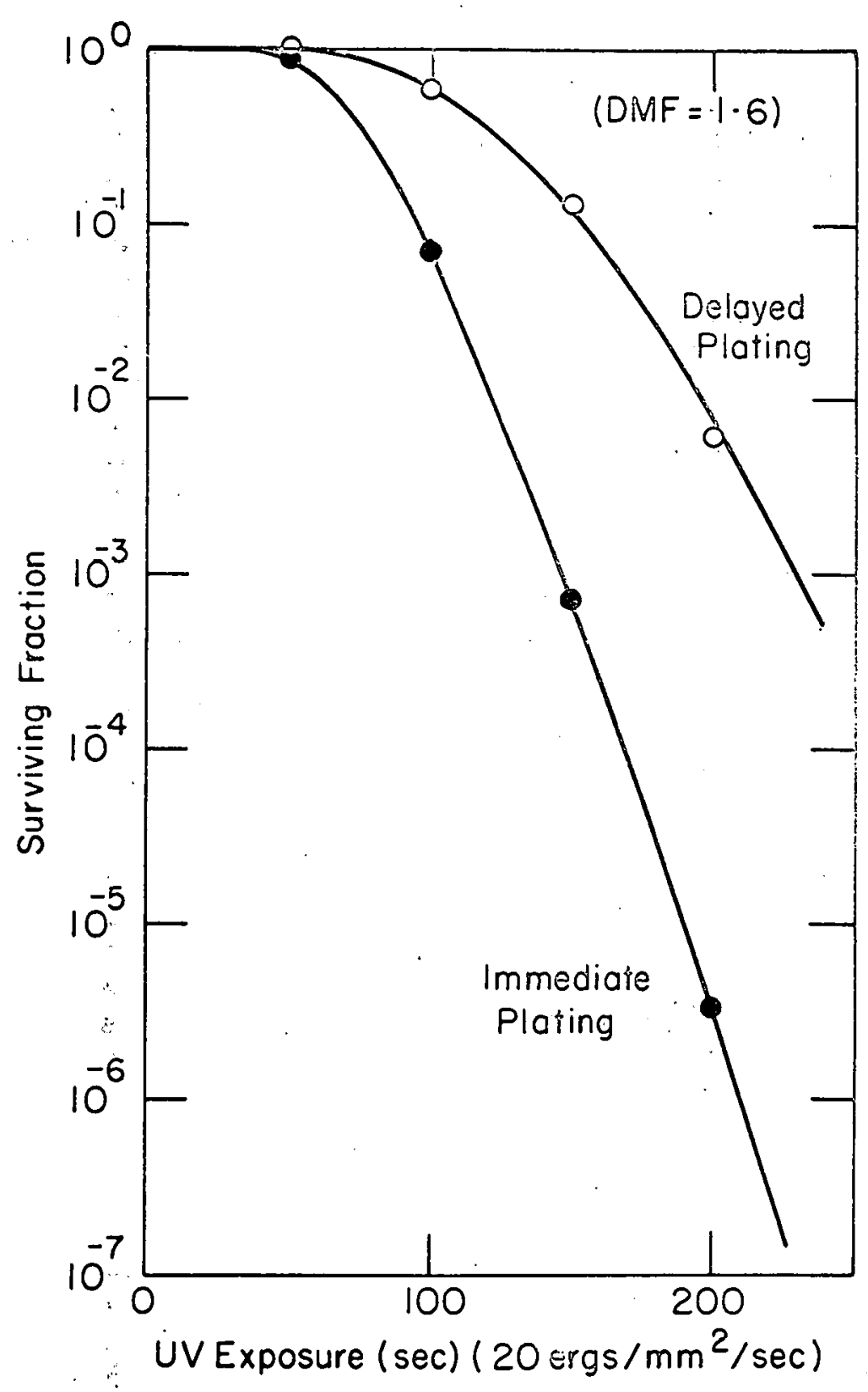

MUB-3964

Fig. 3. Dark recovery of diploid yeast after treatment with $2537-\AA$ ultraviolet light. The cells were harvested from 2-3-day malt agar (Difco) slants, washed twice, filtered through Pyrex wool, and resuspended for irradiation in double glass-distilled water. $\left(10^{6}\right.$ cells $\left./ \mathrm{m} 1\right)$. Lower curve shows survival in distilled water suspensions plated immediately after irradiation; upper curve shows survival in same suspensions after 4 days' storage in the dark at $30^{\circ} \mathrm{C}$. 


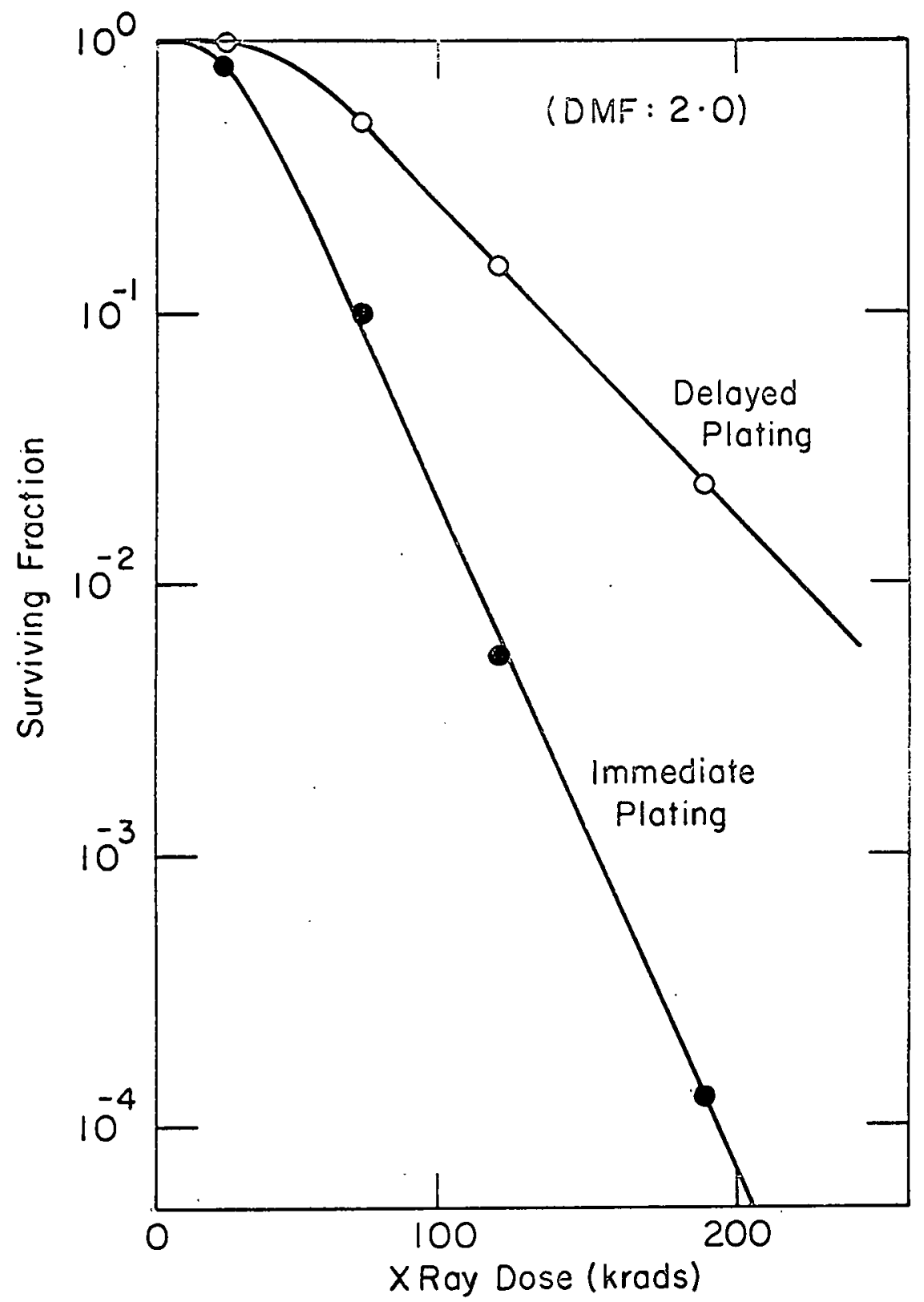

MUB-3965

Fig. 4. Dark recovery of diploid yeast after treatment with 150-kvp $x$ rays in the presence of oxygen. Lower curve shows survival in distilled water suspensions plated immediately after irradiation; upper curve shows survival in same suspensions after 4 days' storage in the dark at $30^{\circ} \mathrm{C}$. 


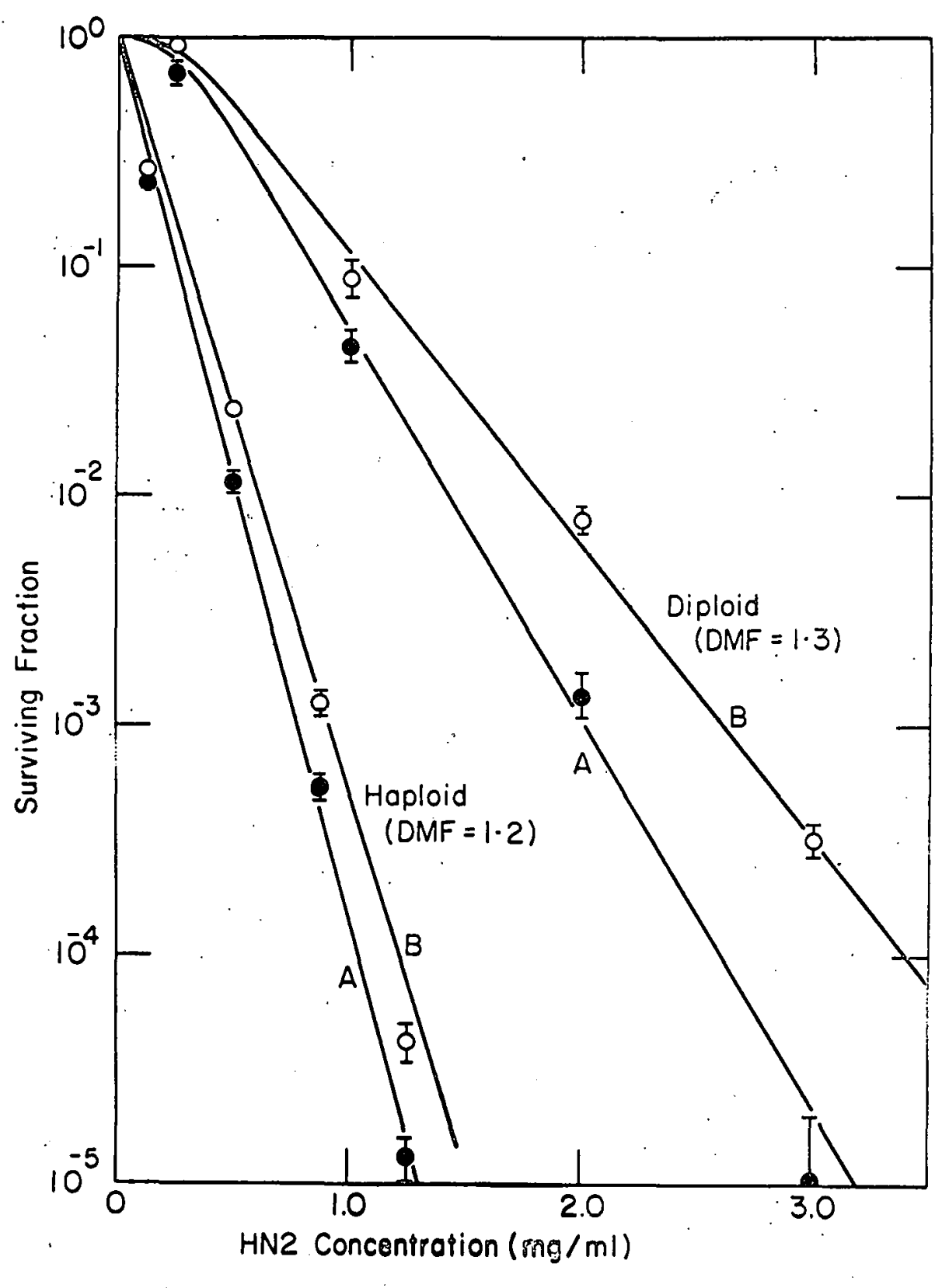

MUB-3966

Fig. 5. Dark recovery of haploid and diploid yeast after treatment with nitrogen mustard. The cells were incubated at $30^{\circ} \mathrm{C}$ for 6 to 8 hours in the presence of HN2; recovery is substantially independent of whether or not the products of HN2 hydrolysis are subsequently removed by washing the cells prior to storage. Curves $A$ show the minimum survival obtained after addition of the mustard, curves $B$. show the survival obtained after 48 hours! storage in phosphate buffer. 


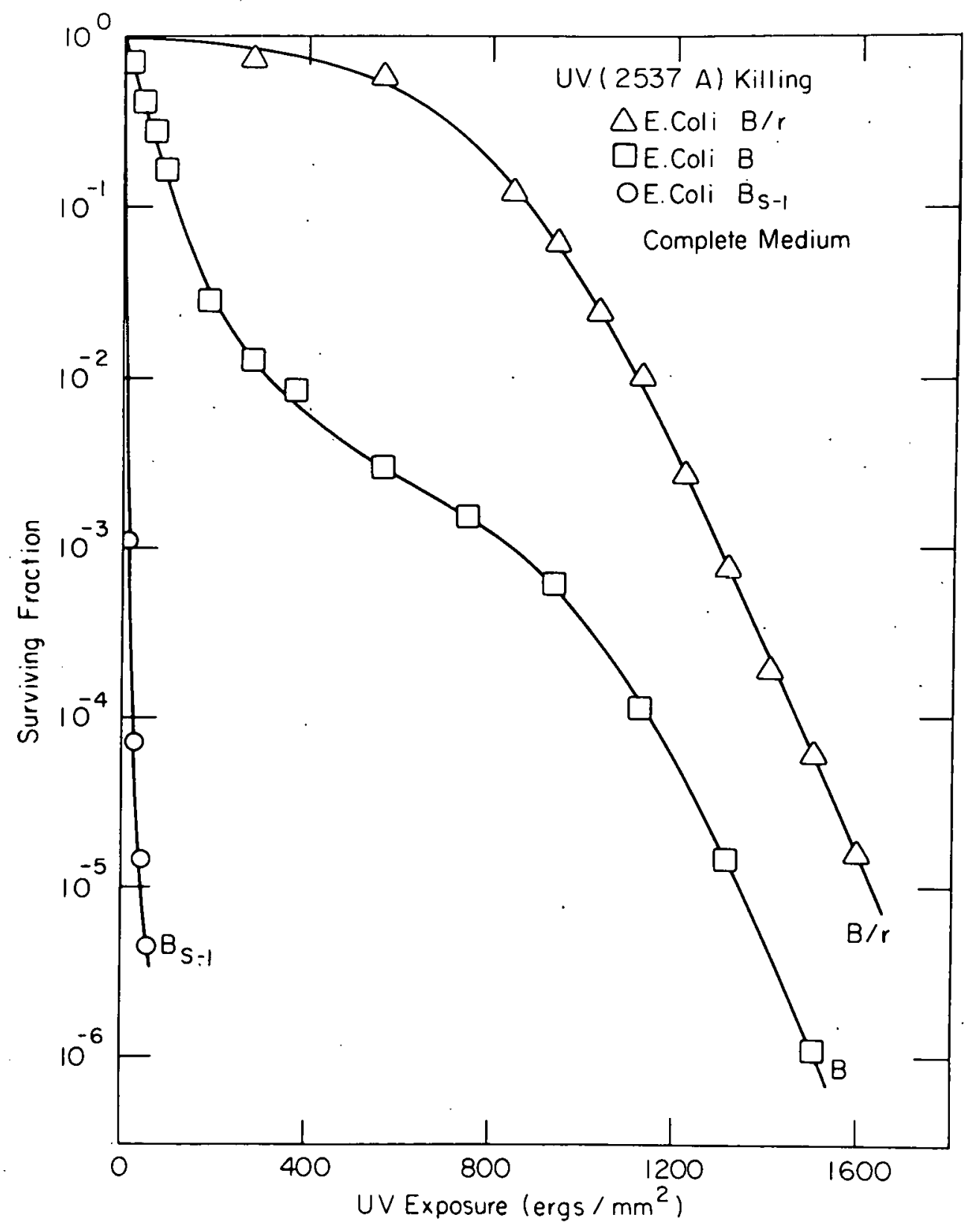

MUB-3967

Fig. 6. Comparative dose-effect curves of E. coli B/r, B and $B_{\text {S-1 }}$ for inactivation by 2537 - $\AA$ ultraviolet light. The cells were harvested from overnight Brain-Heart Infusion (Difco) cultures, washed twice, and resuspended in a.buffered salts solution ( $\mathrm{pH}$ 7.0) for treatment with the inactivating agent and subsequently plated on nutrient (salt) agar plates. 
If dark reactivation in $B / r$ is in fact a multistep process initiated by nuclease attack on DNA, it seems reasonable to think that we have here a general "error-correcting" mechanism in which it is not the altered bases themselves that are recognized by the enzymes but rather some associated secondary structural alterations in the phosphodiester backbone. Thus, one might expect that a variety of defects other than thymine dimers can be repaired by this same mechanism. This idea is consistent with the data presented below on the comparative responses of $\mathrm{E}$. coli $\mathrm{B} / \mathrm{r}$ and the nonreactivating mutant $B_{s-1}$ to inactivation by uv, $x$ rāys, and $\mathrm{HN} 2$, and also with the patterns of cross-resistance 95 and synergistic interactions that occur among these agents in $\mathrm{B} / \mathrm{r} .24$

The survival curves for the inactivation of $E$. coli $B / r ; B$, and $B$ by uv, $\dot{x}$ rays, HN2, and heat $\left(60^{\circ} \mathrm{C}\right)$ under similar growth and incubation conditions are shown in Figs. 6 through 9 . It is clear that for each of the three agents known to inactivate mainly through damage to DNA, E. coli $B_{s-1}$ is substantially more sensitive than $B / r$. (Figs. $6-8$ ), whereas $\overline{a l l}$ three strains are equally sensitive to heat, which at $60^{\circ} \mathrm{C}$ probably inactivates through generalized protein denaturation and enzyme inactivation. It should be noted that the uv survival curve for $B_{S-1}$ is exponential (except for a small resistant tail), whereas $B / r$ has a broad shoulder presumably due to the presence of the reactivation mechanism which becomes saturated or fails at sufficiently high doses. However, even in the 5 th decade of survival, the apparent limiting slope of the $B / r$ curve is still smaller by almost two orders of magnitude than the initial slope of $B_{s-1}$; although it is possible that if the $B / r$ curve were extended to higher doses its slope would ultimately become comparable to that of $\mathrm{B}_{\mathrm{S}-1}$. The uv curve for the parental $B$ strain has an inflection whose origin is still uncertain, although its limiting slope is similar to that of $\mathrm{B} / \mathrm{r}$. In any case, it is obvious from a comparison of the $B / r$ and $B_{s-1}$ curves that the role of parameters such as DNA base composition is vastly overshadowed by that of reactivation mechanisms in controlling photosensitivity.

The survival curves of these three coli strains for HN2 inactivation are strikingly similar in shape to those for uv inactivation (cf. Figs. 6 and 7). However, no thymine dimers are formed by HN2, and since HN2 and uv interact synergistically in $\mathrm{B} / \mathrm{r},{ }^{24}$ it is likely that the same reactivation mechanism that "repairs DNA damage associated with thymine dimers is also capable of repairing HN2-induced defects which cannot be related to thymine dimerization.

Thus, the properties of recovery in yeast and reactivation in $E$. coli are similar in that both appear to be enzymatic, energy-requiring processes, presumably capable of repairing some fraction of the DNA structural defects induced by uv, $\mathbf{x}$ rays, or HN2, but none of the lethal damage produced by heat or acridine-sensitized photodynamic action. 36, 96, 97 The only important difference so far observed is that whereas the dose-modifying factor for yeast recovery after treatment with ionizing : adiation appears to be independent of LET (linear energy transfer along the tracks of the ionizing particles), 98 the sensitivity ratio of $\mathrm{B} / \mathrm{r}$ to $\mathrm{B}_{\mathrm{s}-1}$ decreases with increasing LET ( 3.0 for $x$ rays, 1.4 for Po 210 alpha particles). 96 


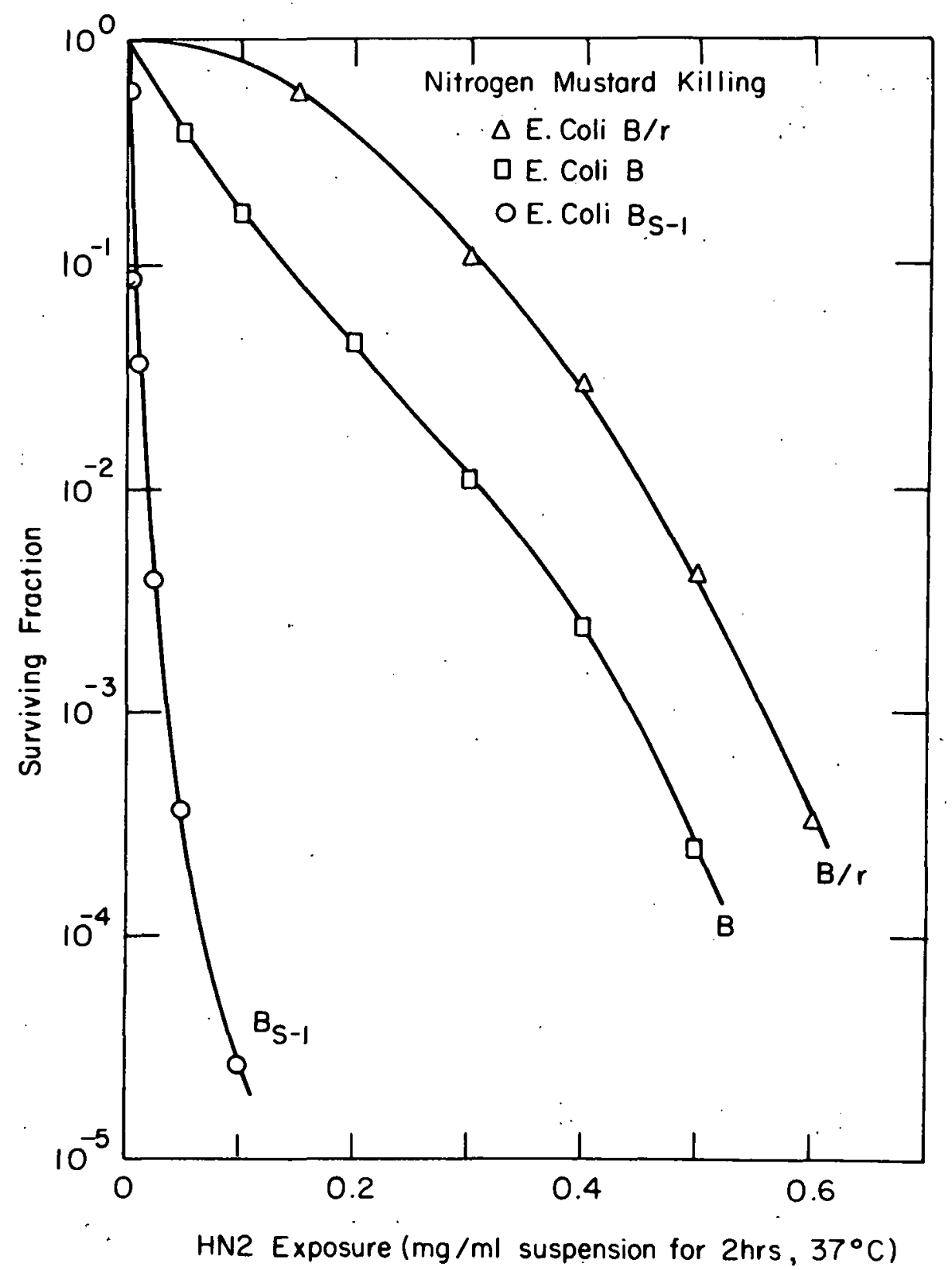

MUB-3968

Fig. 7. Comparative dose-effect curves of $E$. coli $B / r$, $B$ and $B_{S-1}$ for inactivation by nitrogen mustard. The cells were harvested from overnight BrainHeart Infusion (Difco) cultures, washed twice, and resuspended in a buffered.salts solution ( $\mathrm{pH} 7.0$ ) for treatment with the inactivating agent and subsequently plated on nutrient (salt) agar plates. 


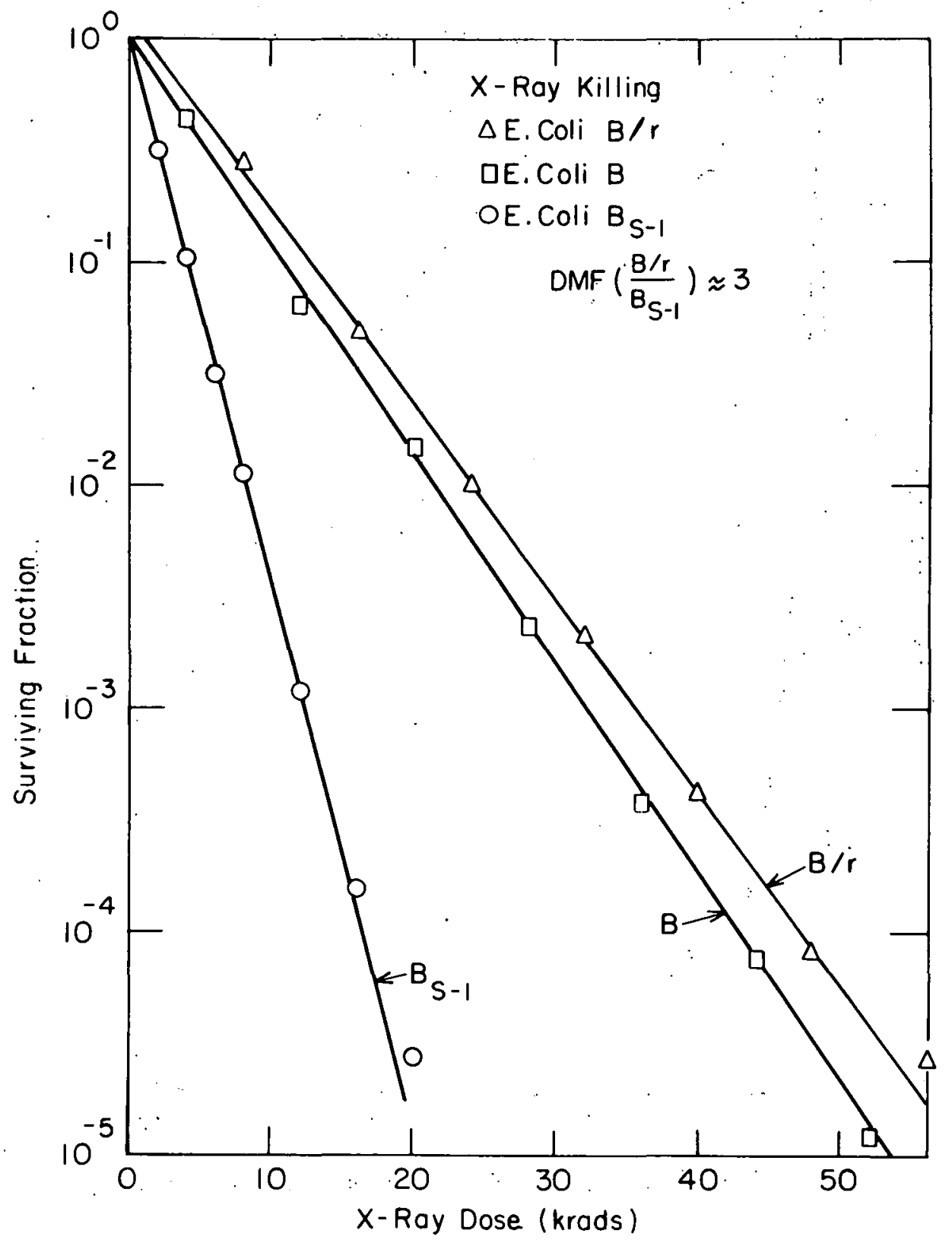

MUB-3969

Fig. 8. Comparative dose-effect curves of E. coli B/r, $B$ and $B_{s-1}$ for inactivation by $150-k v p \cdot x$ rays. The cells were harvested from overnight Brain-Heart Infusion (Difco) cultures, washed twice, and resuspended in a buffered salts solution ( $\mathrm{pH} 7.0$ ) for treatment with the inactivating agent and subsequently plated on nutrient (salt) agar plates. 


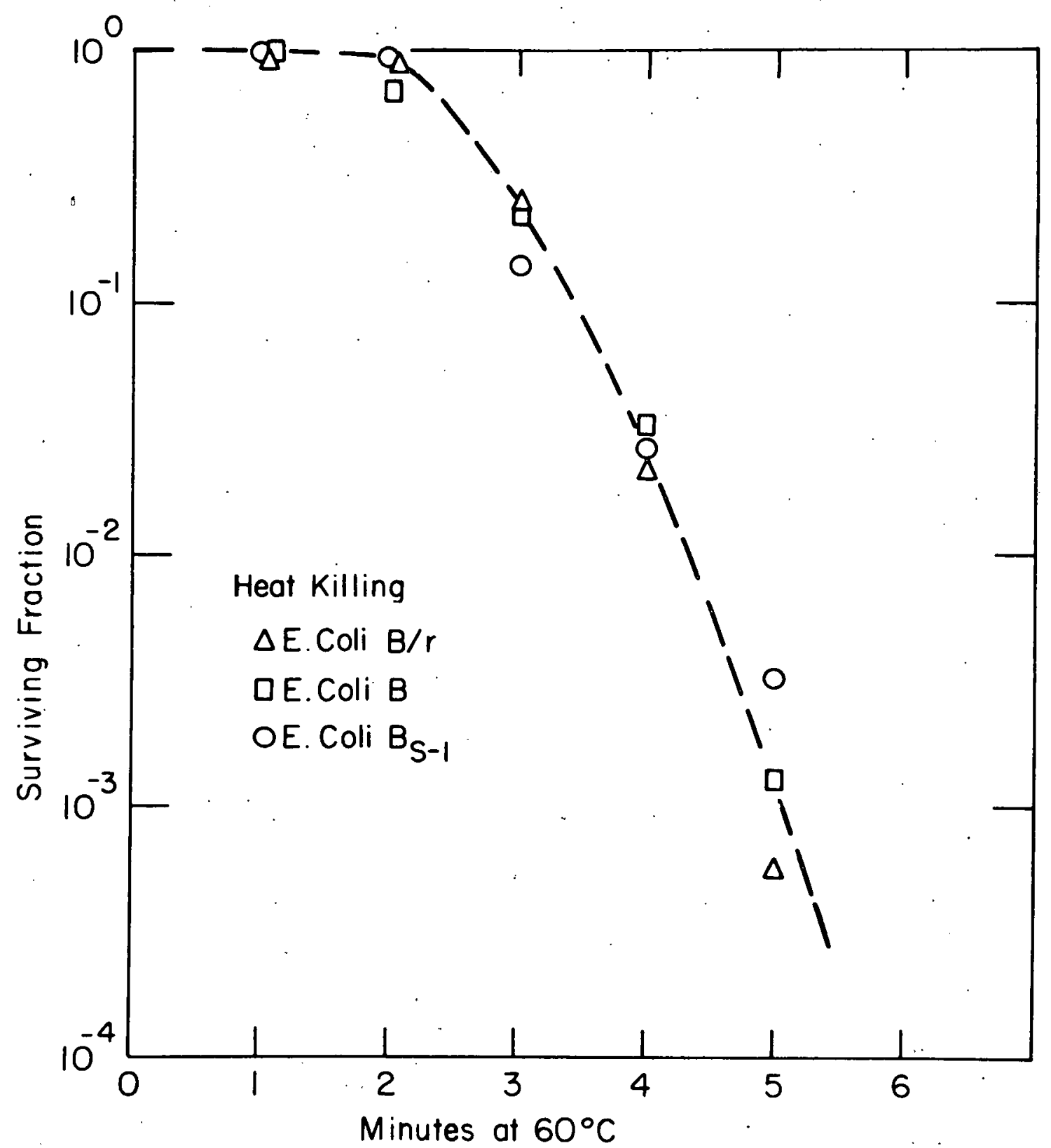

MUB-3970

Fig. 9: Comparative dose-effect curves of E. coli B/r, $B$ and $B_{S-1}$ for inactivation by heat. The cells were harvested from overnight Brain-Heart Infusion (Difco) cultures, washed twice, and resuspended in a buffered salts solution $(\mathrm{pH} 7.0)$ for treatment with the inactivating agent and subsequently plated on nutrient (salt) agar plates. 
It is not yet known whether or not recovery in yeast is initiated by the excision of defective DNA strand segments. However, recovery may be related to somatic recombination, 24 and in preliminary tests of this idea it has been found that the same storage procedure that elicits recovery in diploid yeast also serves to enhance the frequency of allelic recombination in both unirradiated and irradiated cells. 99 Thus, we have before us the tantalizing possibility that the reactivation and recovery processes relevant to radiation and $\mathrm{HN} 2$ damage may constitute a general biochemical mechanism for maining DNA free of certain structural defects, and that at least some of the enzymes involved in recovery are also involved in recombination.

\section{Failure of Reactivation: Sensitization and Synergistic Interactions}

Sensitization, meaning simply an enhanced rate of killing with dose, can, in principle, arise either "directly, "through some modification of the chemical nature of the initial defects which makes them intrinsically more lethal, or "indirectly," through some failure of the reactivation processes. "Direct" sensitization usually involves the fast reactions leading to the formation of the initial defects, a good example of which is the x-ray oxygen effect, which appears to be based on the reaction of oxygen with radiationinduced free radicals in the target molecules. 40, 100 No comparable sensitization effects have been demonstrated for uv, presumably on account of the difficulty of modifying the very fast excitation processes involved in such reactions as thymine dimerization; however, uv protection resulting from energy dissipation through the sensitized fluorescence of acridine orange bound to DNA has been observed in E. coli. 101

The properties of the reactivation and recovery mechanisms described above suggest an alternative mode of sensitization based on the inhibition or saturation of these processes. If repair is an enzymatic, energy-requiring process, it should be possible to interfere with it by blocking the energy supply or by suitable attack on either the enzymes or the DNA substrate. For example, recovery in yeast after either $\mathrm{x}$-ray or uv irradiation can be inhibited by suppressing oxidative phosphorylation, by heating the cells for a few minutes at $60^{\circ} \mathrm{C}$, or by pretreatment with acridine orange or ethyl methane sulphonate. 59 The effects of heat and EMS are shown in Figs. 10 and 11 respectively: 8 minutes of heating at $60^{\circ} \mathrm{C}$, or treatment with $10^{-2} \mathrm{M}$ EMS, reduces the survival of diploid yeast to about $5 \times 10^{-3}$ (curves $D$ ), an $\bar{d}$ in each case the pretreatment completely inhibits recovery after subsequent $x$-ray or uv irradiation; normal recovery is shown in curves $A$, and intermediate effects in curves $B$ and $C$. These experiments suggest that recovery may be suppressed either by thermal inactivation of the repair enzymes (Fig. 10), or by further damage to the DNA substrate (Fig. 12). In addition to suppressing recovery, both of these pretreatments serve to sensitize the cells by reducing the initial shoulders of the survival curves.

The failure of reactivation associated with substrate attack--i. e., the production of additional DNA structural defects--is of interest, since it might provide a common basis for explaining (a) the existence of shoulders on many survival curves, (b) the synergistic interactions that occur among uv, $x$ rays, and $H N 2$, and (c) the sensitizing effects of such mutagens as acridine dyes, alkylating agents, and halogenated-base analogs. If one assumes that the repair of any given defect can be hindered by the existence of 

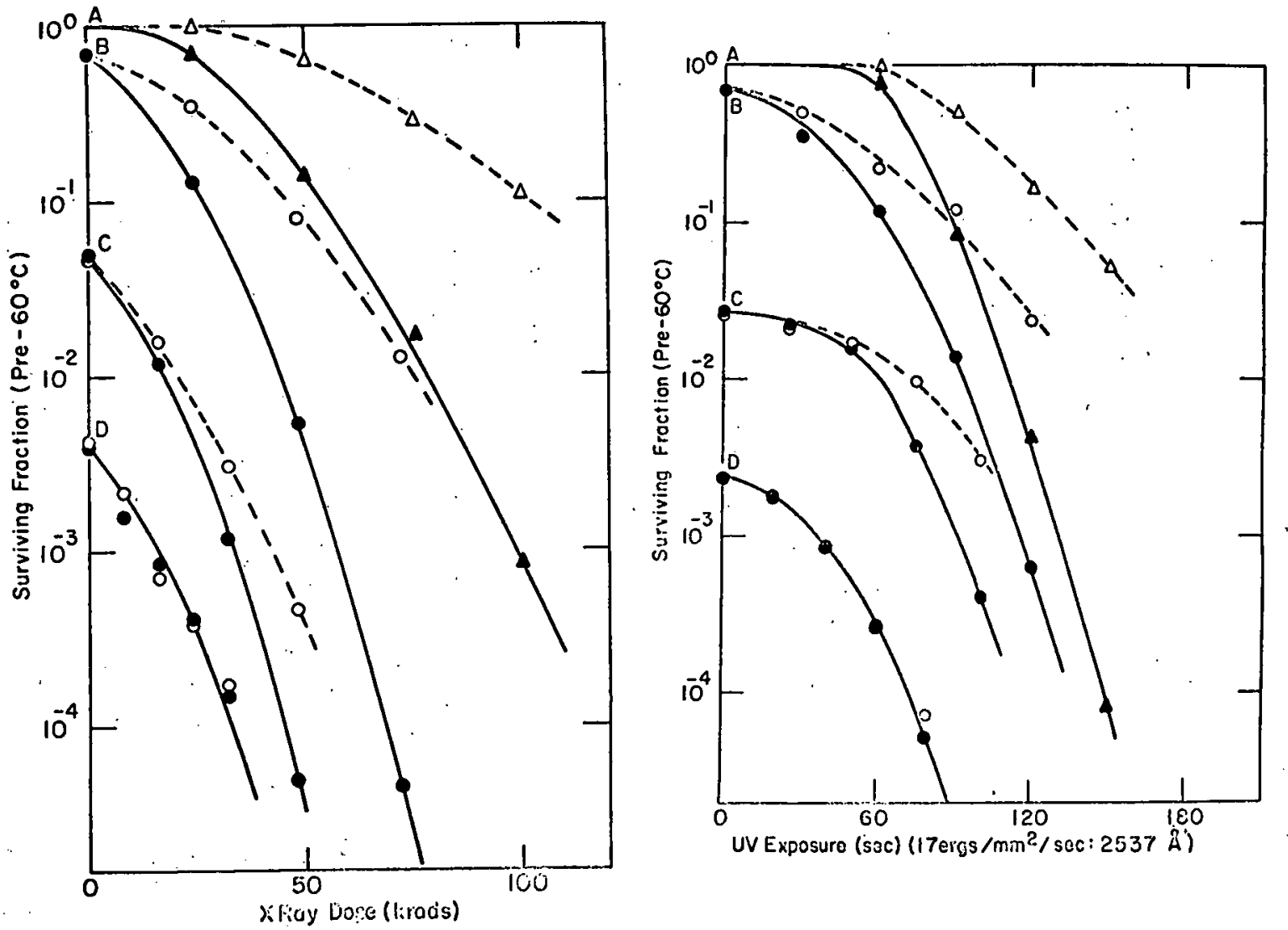

MUB-3971

Fig. 10. The effect of preliminary exposure to heat $\left(60^{\circ} \mathrm{C}\right)$ on the recovery of diploid yeast after treatment with either x rays or 2537 - $\AA$ uv. (Solid symbols and continuous curves indicate survival obtained upon immediate plating; open symbols and broken curves indicate survival obtained if plating is delayed 48 to 72 hours after irradiation.) 

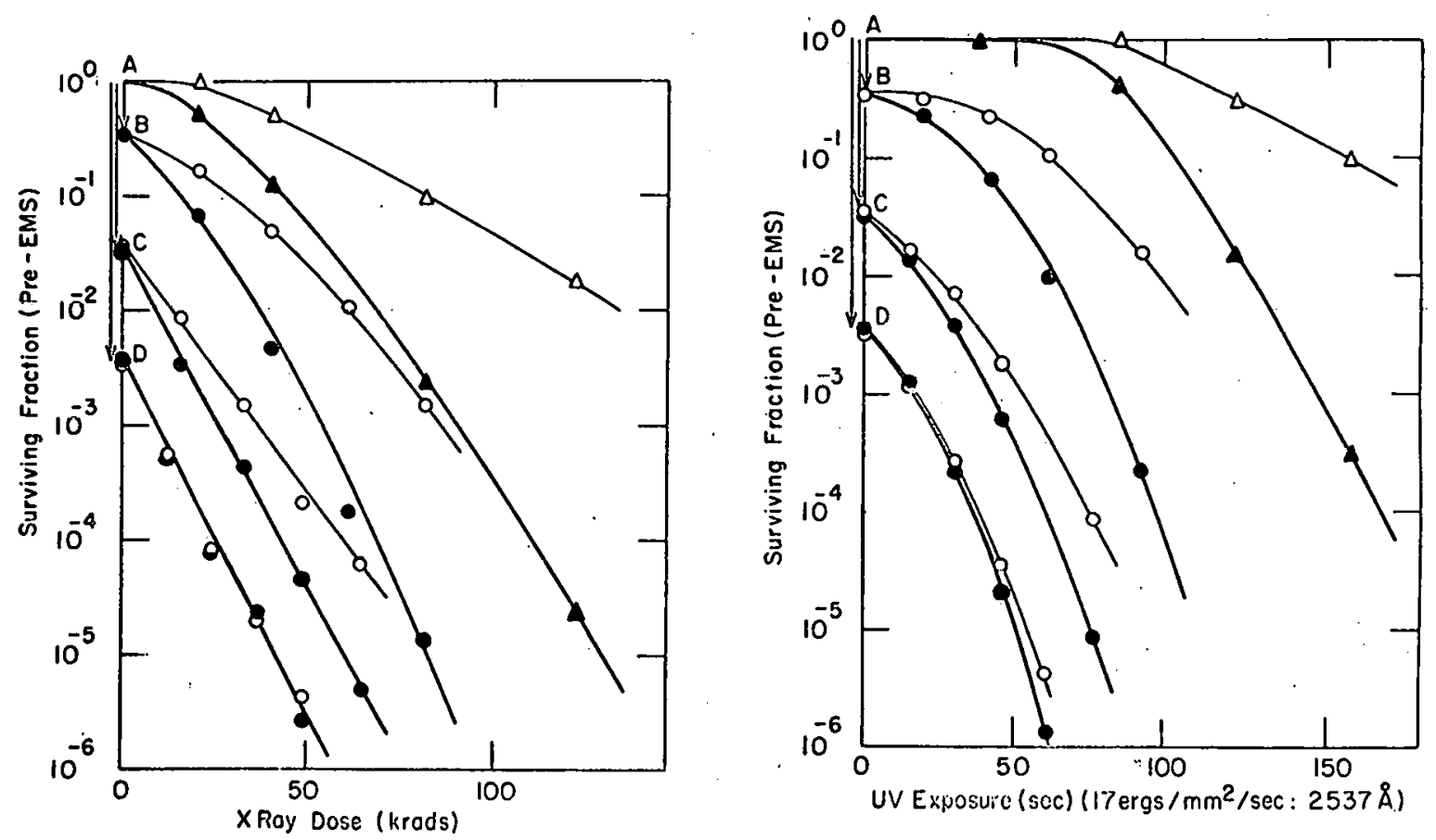

MUB-3972

Fig. 11. The effect of preliminary exposure to $10^{-2} \mathrm{M}$ ethyl methane sulphonate (EMS) on the recovery of diploid yeast after treatment with either $\mathrm{x}$ rays or 2537- $\AA$ uv. (Solid symbols and heavy curves indicate survival obtained upon immediate plating; open symbols and light curves indicate survival obtained if plating is delayed 48 to 72 hours after irradiation.) 
other defects in the polynucleotide chain, it is clear that the net inactivation probability per defect would be. increased in the presence of (a) similar defects produced by the same agent (hence, shoulders on survival curves-except in those cases where no reactivation mechanism exists--or the defects produced up to any practical dose level are so few and sparsely distributed as to be effectively independent of one another), (b) different defects produced by other inactivating agents (hence, synergistic interactions), or (c) the nonlethal defects produced by acridine orange or incorporated base analogs. Failure of reactivation could arise either from the saturation of the system owing to the presence of too many potential binding sites (DNA defects) for the available enzyme supply, 52 or from steric inhibition of binding in the region of two or more closely spaced defects. Also, it is possible that in some cases repair could be abortive and actually lead to the creation of more highly lethal defects, i. e., DNA double-strand breaks might arise from the attempted excision of defects near the site of preexisting breaks in the opposite strand.

In addition to accounting for the existence of a shoulder on the uv survival curve for $E$. coli $B / r$. and its absence for the nonreactivating mutant $B_{s-1}$ (Fig. 6 ), and the inhibition of recovery and shoulder removal in yeast by treatment with EMS (Fig. 11) or acridine orange, this scheme can also be used to elucidate the synergistic uv-x-ray, HN2-x-ray and $\mathrm{HN} 2-$ uv interactions that occur both in $\mathrm{B} / \mathrm{r}$ and diploid yeast. 7,24 [No such interactions have been observed in the nonreactivating mutants of E. coli, nor do the uv-x or HN2-x interations occur in haploid yeast, which is unique in its inability to recover after $x$-irradiation; on the other hand, haploid yeast is capable of some recovery after uv or HN2 treatment, and correspondingly there exists an $\mathrm{HN}_{2}-\mathrm{uv}$ interaction. 24,86 ]

The main features of the uv-x-ray interaction in $E$. coli $B / r$ are shown in Figs. 12 through 14: First, graded, prelimināry uv exposure increases the $x$-ray sensitivity up to a factor of 3 over that of control cells which have not been exposed to uv (Fig. 12); the x-ray sensitivity of E. coli $\mathrm{B}_{\mathrm{S}-1}$ is similarly three times greater than that of $\mathrm{B} / \mathrm{r}$ (Fig. 8). About onehalf of the uv-induced, $x$-ray-sensitizing damage is photoreactivable. Secondly, graded, preliminary $x$-ray exposure partially removes the shoulder but has no effect on the apparent limiting slope of the uv survival curve (Fig. 13). And thirdly, the total kill for any given pair of $x$-ray and uv exposure is independent of the order in which they are given (Fig. 14), despite the contrast in the kinetics of the interaction (Figs. 12 and 13). This third point rules out the possibility that the synergism is based on reactions between the short-lived products of either radiation, or that any of the structural defects produced by one are directly "seen" by the other. Rather it suggests the failure of a postirradiation process, such as a reactivation mechanism, commonly associated with DNA defects produced by either radiation. This interpretation is supported by the fact that preliminary uv irradiation produces a maximum threefold increase in $x$-ray sensitivity, which corresponds to the $x$-ray sensitivity ratio between $B / r$ and $B$ also that the $x$-ray sensitizing effect of uv saturates out-as the uv survival curve begins its slow approach to a limiting slope (doses $\geqslant 1200 \mathrm{ergs} / \mathrm{mm}^{2}$ ). 


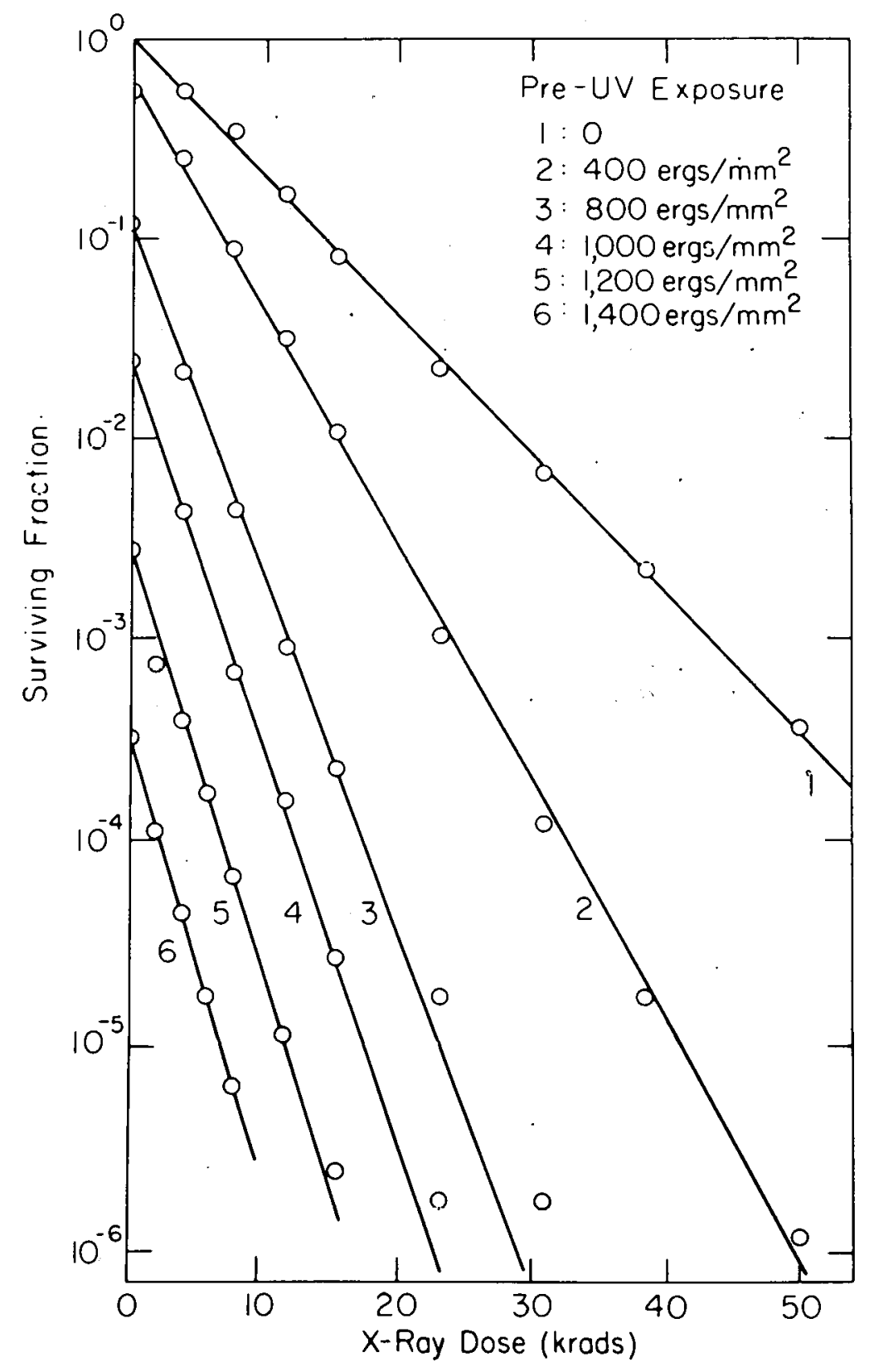

MUB-3973

Fig. 12. Synergistic interaction between uv and $x$ rays in $\mathrm{E}$. coli $\mathrm{B} / \mathrm{r}$ : preliminary uv exposure increases the slope of the subsequent $x$-ray survival curves. In this experiment the cells were grown in $1 \%$ unbuffered peptone (Difco) and resuspended for irradiation. in distilled water. 


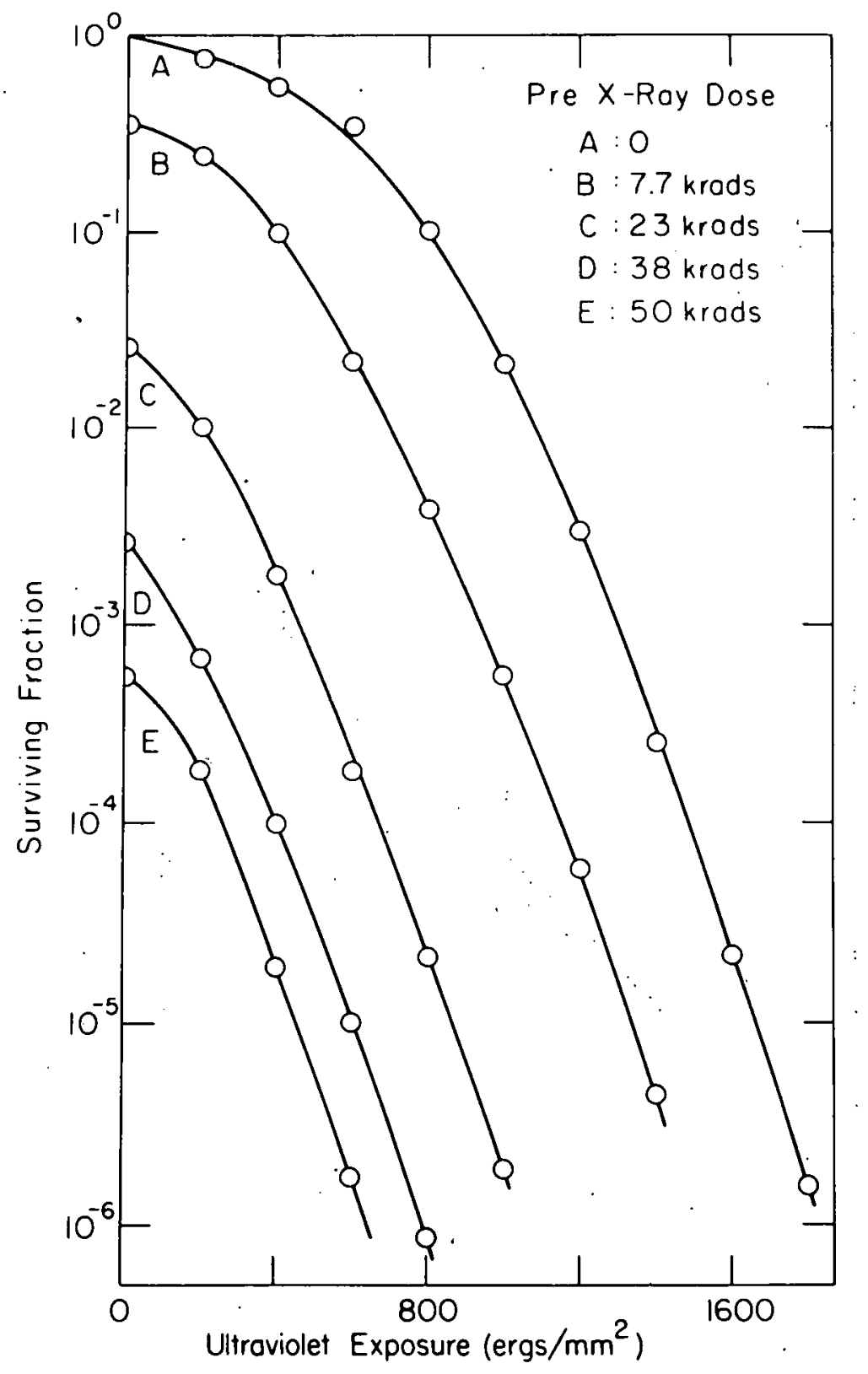

MUB-3974

Fig. 13. Synergistic interaction between $x$ rays and uv in E. coli $\mathrm{D} / \mathrm{r}$ : preliminary $\mathrm{x}$-ray exposure reduces the shoulder of the subsequent uv survival curve but has no effect on its limiting slope. 


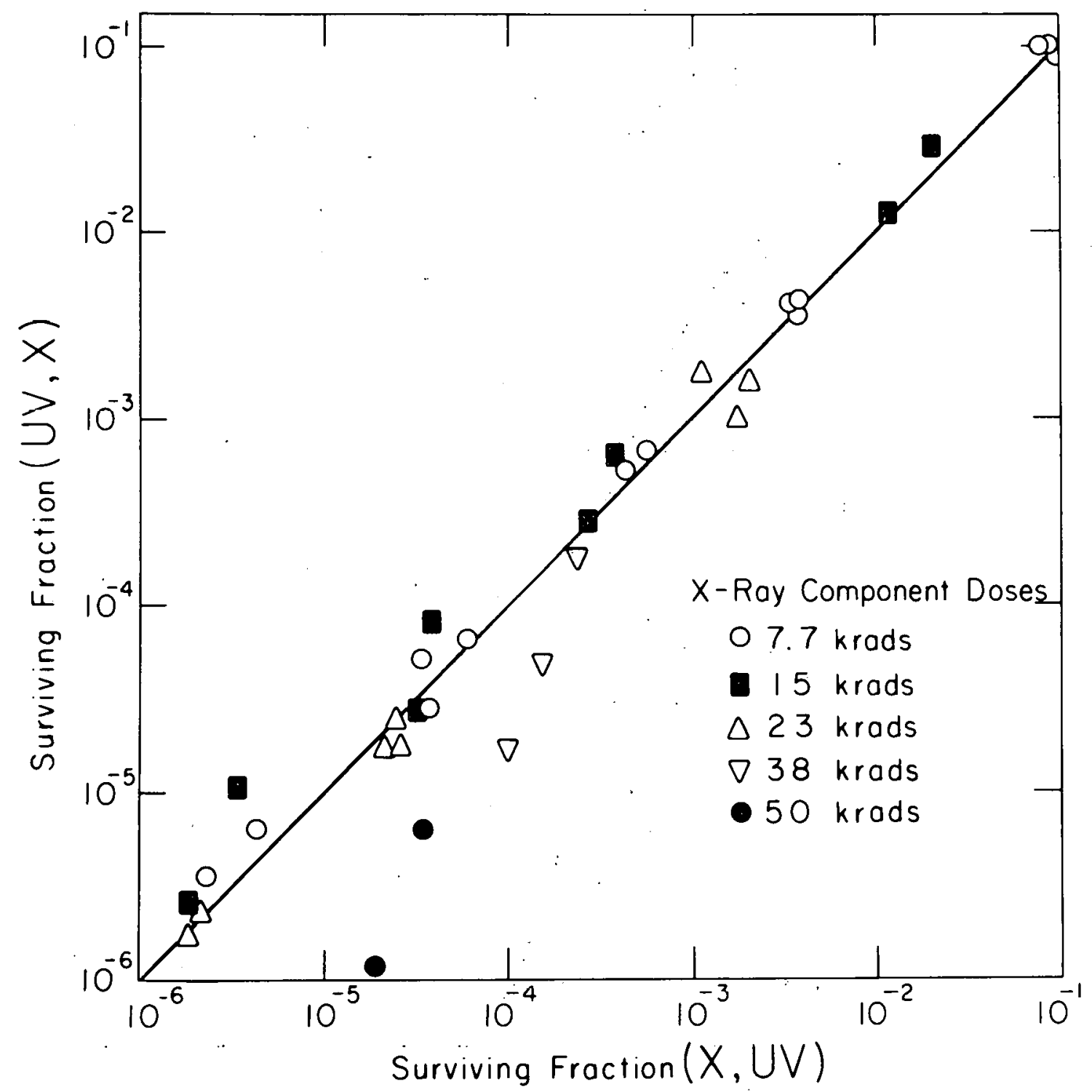

MUB-3975

Fig. 14 
Fig. 14. The fraction of cells which survive any combination of $\mathrm{x}-\mathrm{ray}$ and uv doses is independent of the order in which the two irradiations are given. For each point on this plot the abscissa is the survival level reached by some ordered pair of doses ( $x$ ray, uv), with the x-ray dose given first; the corresponding ordinate is the survival level reached by the same pair of doses given in the reverse order (uv, $x$ ray). The total number of cells killed is independent of the irradiation order to the extent that the points fall on the diagonal line drawn through the origin. Treating the corresponding ( $x$ ray, $u v$ ) and (uv, $x$ ray) survival levels as paired data, there is no statistically significant difference between them (Student's $t$ ratio 0.74 for 33 degrees of freedom). Further experiments have shown that the apparent departure for the high$x$-ray component points was due to experimental error. 
All kinetic features of the interaction can be accounted for if it is assumed that in the biological dose range the defects produced by $x$ rays are so sparsely distributed as to be effectively independent of one another (exponential $x$ ray inactivation), whereas the defects produced by uv become sufficiently numerous to hinder reactivation (shoulder in uv survival curve): failure of reactivation due to the presence of uv-induced defects would serve at most to increase the slope of the $x$-ray curve up to a factor of 3 , comparable to that of $B_{s-1}$; conversely, the presence of $x$-ray-induced defects would serve to decrease the shoulder of the uv curve, as the uv dose needed to saturate the reactivation mechanism would thereby be reduced.

Similar interactions exist in $\mathrm{B} / \mathrm{r}$ between $\mathrm{HN} 2$ and $\mathrm{x}$ rays (Fig. 15) and HN2 and uv, 24 although in these cases it is not feasible technically to determine whether or not the total kill is precisely independent of the ordering of the inactivating treatments. Also, it should be noted that the apparent magnitude of the $\mathrm{x}$-ray sensitization produced by pretreatment with HN2 is less than that for uv (a factor of 2 for HN2 versus 3 for uv, Fig. 16) which might suggest that relatively few of the $H N 2$-induced defects are susceptible of repair.

Summary

We have described what appears to be the major cause of death in bacteria treated with ultraviolet light, $x$ rays or "nitrogen mustard (HN2): all these agents produce structural defects in. DNA which, unless repaired, are likely to inhibit DNA synthesis or cause some error in protein synthesis, which leads to cell death. Thus, survival is determined by the net probability that these defects either persist and prove lethal, or are repaired after irradiation during the first few hours of incubation on the plating medium. The apparent correlations of uv, $x$-ray, and HN2 sensitivity with DNA base composition suggest that the relevant damage caused by these agents is associated with adenine-thymine base pairs for uv and guanine-cytosine base pairs for $x$ rays and HN2. Intrastrand thymine dimers probably account for about 50 to $70 \%$ of the biological damage caused by uv, and enzymatic photoreactivation is based upon the cleavage of these dimers.

Both diploid yeast and $E$. coli $B / r$ possess enzymatic, energyrequiring reactivation mechanisms capable of repairing DNA structural defects caused by uv, $x$ rays, or HN2; on the other hand, these repair processes cannot reverse either thermal $\left(60^{\circ} \mathrm{C}\right)$ or acridine-sensitized photodynamic damage, and in fact are inhibited in the presence of acridine dyes and in cells which have been pretreated either with heat, or with the monofunctional alkylating agent ethyl methane sulphonate (EMS).

It is suggested that enhanced killing due to the failure of reactivation in the presence of too numerous or too closely spaced DNA defects may be a common factor underlying (a) the existence of shoulders on many doseresponse curves, (b) the synergistic interactions among DNA-specific inactivating agents, and (c) the sensitization produced by substances that are either incorporated into DNA (halogenated base analogs) or bind to it (acridine dyes). 


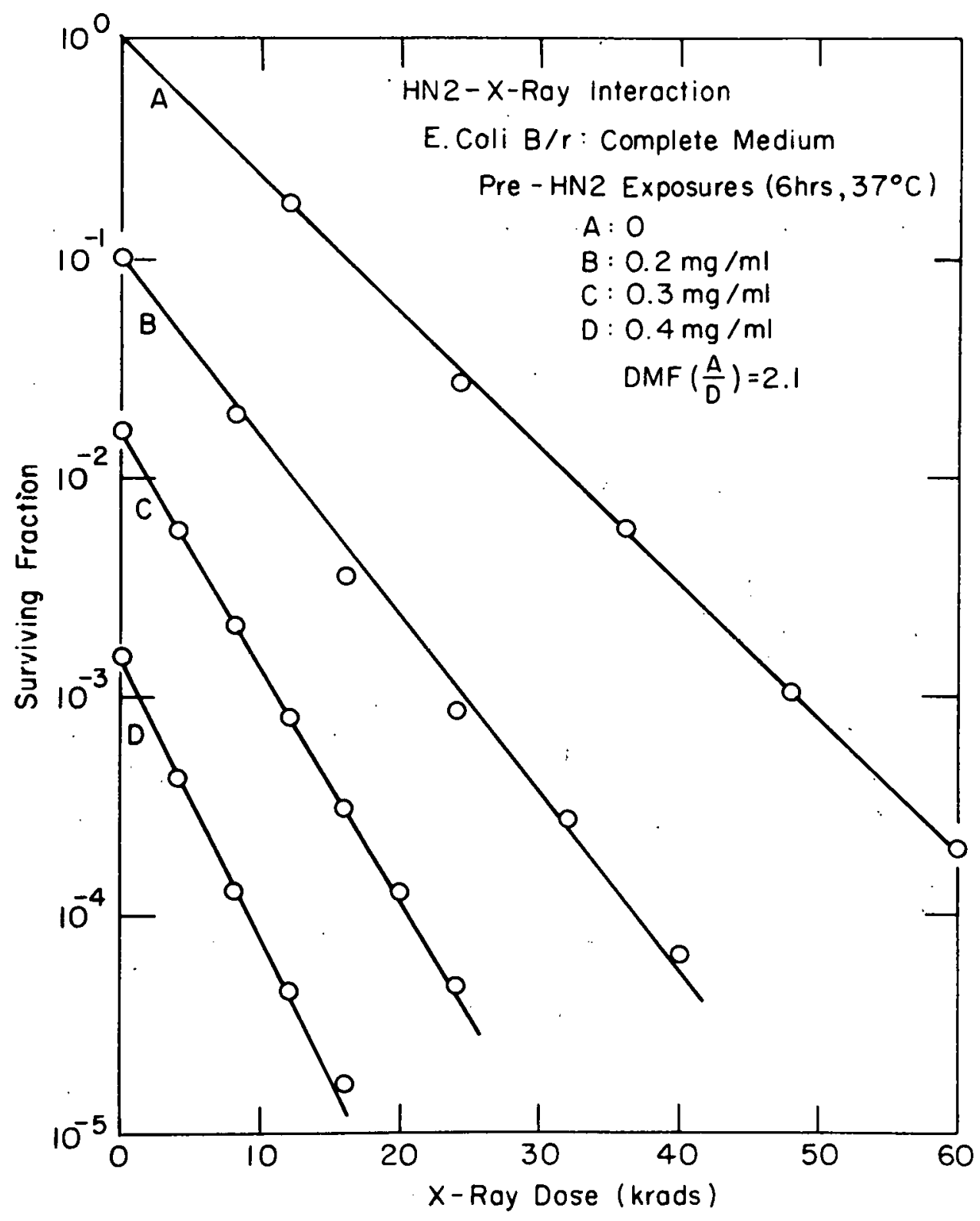

MUB-3976

Fig. 15. Synergistic interaction between $\mathrm{HN} 2$ and $\mathbf{x}$ rays in E. coli B/r. The cells were incubated in the presence of $\overline{\mathrm{HN2}}$ for 6 hours at $37^{\circ} \mathrm{C}$ prior to irradiation. No such $\mathrm{x}$-ray sensitization can be produced by $\mathrm{HN} 2$ in haploid yeast. 


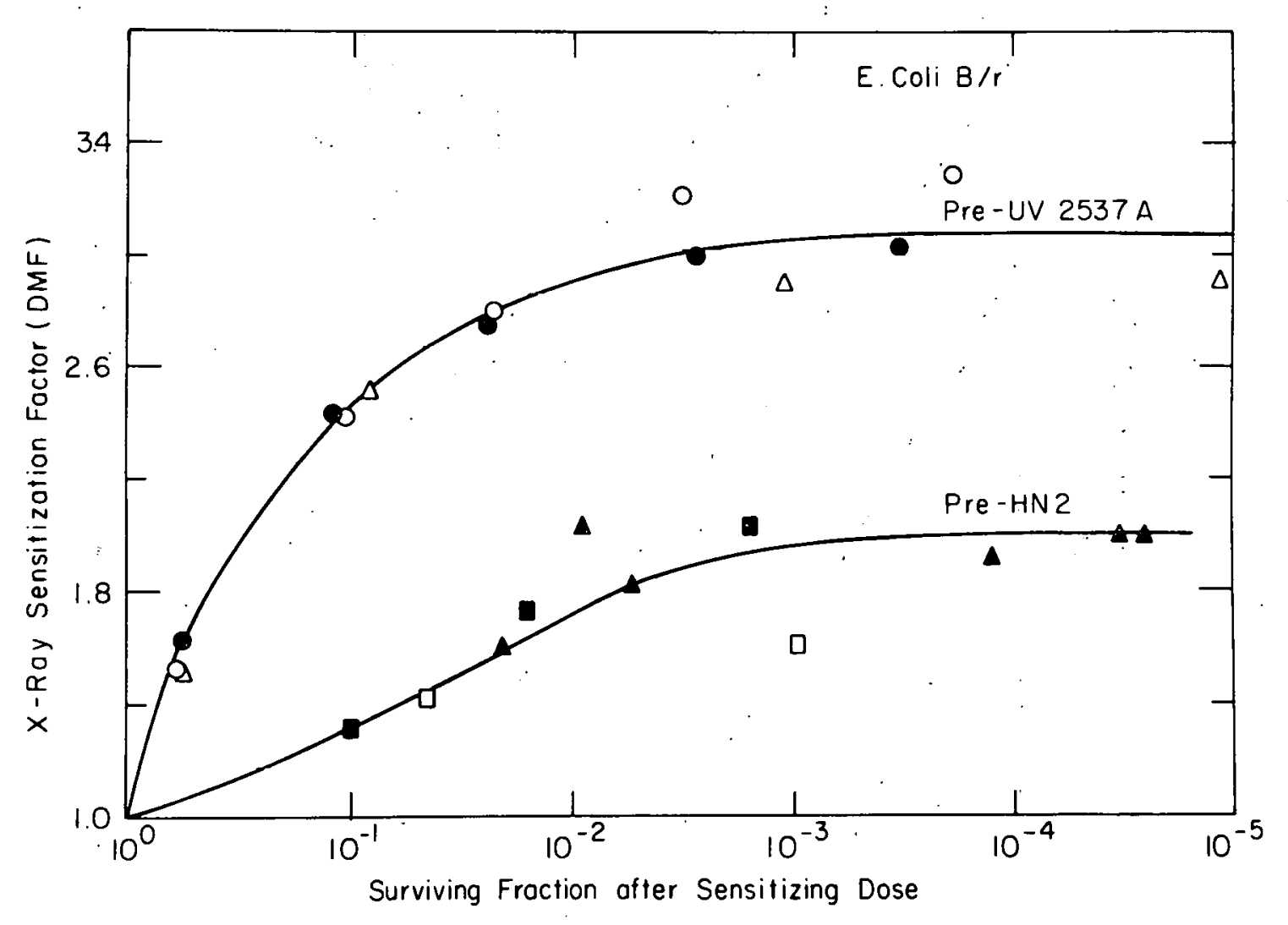

MUB-3977

Fig. 16. X-ray sensitization of E. coli B/r produced by preliminary exposure to uv or $\overline{\mathrm{HN}} 2$, plotted as a function of the initial survival level reached by the sensitizing uv or HN2 treatment. 
In view of the existence of all possible synergistic interactions among uv, $x$ rays, and $H N 2$ in diploid yeast and $E$. coli $B / r$, the absence of such interactions in those situations where no reactivation or recovery is known to occur, and the similarity in the comparative responses of $\mathrm{E}$. coli $\mathrm{B} / \mathrm{r}$, $B$, and $B_{s-1}$ to inactivation by $u v$ or HN2, it is possible that the rexists only one dark reactivation mechanism and that the enzymes involved are specific for DNA secondary structural alterations which may or may not be associated with damaged bases. Such a lack of specificity for the damaged bases themselves appears to be consistent with the recently discovered reactivation mechanism in which repair is initiated by nuclease excision of defective strand segments.

This description of the photoinactivation of bacteria is conceptually simple and broad in scope, although these desirable qualities may reflect more our ignorance than our insight into the complex processes that are involved. However, the study of dark reactivation and recovery phenomena shows promise of rewarding us with a deeper understanding of the temporal continuity of the gene.

\section{Acknowledgments}

I wish to thank Aldona Kruvelis, Barry S. Brunsden, and David E. Axelrod for their help in carrying out these experiments. Figures 3, 4, 5, 10 and 11 were kindly provided by Dr. M. H. Patrick from his Ph. D. thesis ("Intracellular Repair of Radiation Damage", University of Chicago, Division of Biological Sciences, 1964). Work on this paper was aided by many critical discussions with Dr. David Freifelder and Dr. R. B. Uretz.

\section{References}

1. J. R. Loofbourow, Growth.12 (Suppl.), 77 (1948).

2. M. R. Zelle and A. Hollaender, in Radiation Biology, A. Hollaender, Ed. (McGraw-Hill, New York, 1955), vol. II, p. 365.

3. R. B. Setlow, Brookhaven Symp. Biol. 14, 1 (1961).

4. J. H. Stuy, Doctoral Thesis, State University of Utrecht, 1961.

5. A. C. Giese, Ed., Photophysiology, (Academic Press, New York, 1964) vol. II, chapters $17-20$.

6. A. D. McLaren and D. Shugar, Photochemistry of Proteins and Nucleic Acids (Pergamon Press, London, 1964).

7. R. H. Haynes; in Physical Processes in Radiation Biology, L. Augenstein, R. Mason, and B. Rosenberg, Eds. (Academic Press, New York, 1964), p. 50.

8. R. B. Roberts and E. Aldous, J. Bacteriol. 57, 363 (1949).

9. T. Alper and N. E. Gillies, J. Gen. Microbiol. 18, 461 (19.58).

10. G. E. Stapleton and M. S. Engel, J. Bacteriol. 80, 544 (1960).

11. R. A. Morton and R. H. Haynes, Abstract TB10, Biophysical Society, Chicago, 1964. 
12. N. O. Kjeldgaard, Doctoral Thesis, University of Copenhagen 1963.

13. H. D. Barner and S. S. Cohen, J. Bacteriol. 71, 149 (1956).

14. C. E. Helmstetter and D. J. Cummings, Proc. Natl. Acad. Sci. U. S. 50, 767 (1963).

15. C. E. Helmstetter and R. B. Uretz, Biophys. J. 3, 35 (1963).

16. K. G. Zimmer, Studies on Quantitative Radiation Biology (Oliver and Boyd, Edinburgh "\& London, 1961).

17. A. Norman, J. Cell. Comp. Physiol. 44, 1 (1954).

18. C. Auerbach and J. M. Robson, Proc. Roy. Soc. Edinburgh B62, 271 (1947).

19. C. P. Swanson, J. Cell Comp. Physiol. 39 (Suppl. 1): 27 (1952):

20. S. Wolff, in Mechanisms in Radiobiology, M. Errera and A. Forssberg, Eds:, (Academic Press, New York, 1961) vol. I, p. 419.

21. P. C. Koller, Prog. Biophys. Biophys. Chemistry 4; 195 (1954).

22. R. Latarjet and B. Ephrussi, Compt. Rend. 229, 306 (1949).

23. R. K. Mortimer, Brookhaven Symp. Biol. 14, 62 (1961).

24. R. H. Haynes and W. R. Inch, Proc. Natl. Acad. Sci.. U. S: 50, 839 (1963).

25. R. E. Zirkle, J. Cell Comp. Physiol. 2, 251 (1932).

26. R. C. von Borstel and S. Wolff, Proc. Natl. Acad. Sci. U. S. 41, 1004 (1955).

27. A. S. Goldman and R. B. Setlow, Exptl. Cell Res. 11, 146 (1956).

28. R. E. Zirkle, Advan. Biol.. Med. Phys. 5, 103 (1957).

29. C. L. Smith, Intern. Rev. Cytol. 16, 133 (1964).

30. F. L. Gates, Science 68, 479 (1928).

31. F. L. Gates, J. Gen. Physiol. 13, 231 (1929); ibid. 13, 249 (1929); ibid. 14, 31 (1930).

32. A. Hollaender and W. D. Claus, J. Gen. Physiol. 19, 753 (1936).

33. A. Hollaender and C. W. Emmons, Cold Spring Harbor Symp. Quant. Biol. 9, 179 (1941).

34. L. J. Stadler and F. M. Uber, Genetics 27, 84 (1942).

35. J. S. Kirby-Smith and D. L. Craig, Genetics 42, 176 (1957).

36. R. B. Setlow, Advan. Biol. Med. Phys. 5, 37 (1957).

37. M. E. Gaulden and R. P. Perry, Proc. Natl. Acad. Sci. U. S. 44, 553 (1958).

38. J. Seed, Proc. Ròy. Soc. London B 152, 387 (1960).

39. T. Alper, Phys. Med. Biol. 8, 365 (1963).

40. P. Howard-Flanders, J. Levin, and L. Theriot, Radiation Res. 18, $593 \cdot(1963)$. 
41. A. Wacker, A. Trebst, D. Jacherts, and F. Weygand, Z. Naturforsch. 9B, 616 (1954).

42. S. Greer and S. Zamenhof, Abstract, American Chemical Society, 131 st Meeting, p. 3C (1957).

43. H. S. Kaplan, K. C. Smith, and P. Tomlin, Nature 190, 794 (1961).

44. Z. Lorkiewicz and W. Szybalski, Biochem. Biophys. Res. Commun. 2, 413 (1960).

45. S. Greer, J. Gen. Microbiol. 22, 618 (1960).

46. H. S. Kaplan, K. C. Smith, and P. Tomlin, Radiation Res. 16, 98 (1962).

47. R. P. Boyce and R. B. Setlow, Biochem. Biophys. Acta 68, 446 (1963).

48. B. Djordjevic and W. Szybalski, J. Exptl. Med. 112, 509 (1960).

49. N. Delihas, M. A. Rich, and M. L. Eidinoff, Radiation Res. 17, 479 (1962).

50. R. L. Erikson and W. Szybalski, Radiation Res. 20, 252 (1963).

51. A. W. Kozinski and W. Szybalski, Virology 9, 260 (1959).

52. R. M. Litman and A. B. Pardee, Biochim. Biophys. Acta 42, 117 (1960).

53. F. W. Stahl, J. M. Crasemann, L. Okun, E. Fox, and C. Laird, Virology 13, 98 (1961).

54. P. Howard-Flanders, R. P. Boyce, and L. Theriot, Nature 195, 51 (1962).

55. R. B. Setlow and R. P. Boyce, Biochim. Biophys. Acta 68, 455 (1963).

56. Z. Opara-Kubinska, Z. Lorkiewicz, and W. Szybalski, Biochem. Biophys. Res. Commun. $\underline{4}, 288$ (1961).

57. W. Szybalski and Z. Lorkiewicz, in Strahleninduzierte Mutagenese, Erwin-Baur-Gedächtinisvorlesungen II (H: Stubbe and H. Bohme, Eds. ), Abhandl. Deutsch. Akad. Wiss. Berlin Kl. Med. 1, 61 (1962).

58. K. C. Smith, Biochem. Biophys. Res. Commun. 6, 458 (1962).

59. M. H. Patrick and R. H. Haynes, Radiation Res., in press.

60. T. Alper, Nature 200, 534 (1963).

61. G. Scholes, J. F. Ward, and J. Weiss, J. Mol. Biol. 2, 379. (1960).

62. R. Latarjet, B. Ekert, and P. Demerseman, Radiation Res. Suppl. 3, 247 (1963).

63. W. R. Guild, Radiatión Res. Suppl. 3, 257 (1963).

64. P. Brookes and P. D. Lawley, Biochem. J. 80, 496 (1961).

65. W. C. J. Ross, Biological Alkylating Agents (Butterworths, London, 1962).

66. R. B. Setlow, P. A. Swenson, and W. L. Carrier, Science 142, 1464 (1963). 
67. R. Beukers and W. Berends, Biochim. Biophys. Acta 41, 550 (1960).

68. A. Wacker, H. Dellweg, and D. Weinblum, Naturwissenschaften 47, 477 (1960).

69. D. M. Freifelder and P. F. Davison, Biophys. J. 3, 97 (1963).

70. R. B. Setlow, Biochim. Biophys. Acta 49, 237 (1961).

71. H. E. Johns, S. A. Rapaport, and M. Delbruck, J. Mol. Biol. $\underline{4}$, 104 (1962).

72. R. B. Setlow and J. K. Setlow, Proc. Natl. Acad. Sci. U. S. 48, 1250 (1962).

73. C. S. Rupert, J. Cell. Comp. Physiol. 58 (Suppl. 1), 57 (1961).

74. D. L. Wulff and C. S. Rupert, Biochem. Biophys. Res. Commun. 7 , 237 (1962).

75. J. K. Setlow and R. B. Setlow, Nature 197, 560 (1963).

76. A. Kelner, J. Bacteriol. 65, 252 (1953).

77. F. J. Bollum and R. B. Setlow, Biochim. Biophys. Acta 68, 599 (1963).

78. J. K. Setlow, Photochem. Photobiol. 2, 393 (1963).

79. J. W. Drake, J. Mol. Biol. 6, 268 (1963).

30. H. S. Kaplan and R. Zavarine, Biochem. Biophys. Res. Commun. ${ }_{\text {, }}$ 432 (1962).

81. R. H. Haynes and D. Axelrod, J. Cell Biol. 19, 33A (1963).

82. A. Müller, W. Köhnlein, and K. G. Zimmer, J. Mol. Biol. 7, 92 (1963).

83. E. P. Geiduschek, Proc. Natl. Acad. Sci. U. S. 47, 950 (1961).

84. A. Hollaender (Ed.), Radiation Protection and Recovery (Pergamon Press, London, 1960).

35. F. H. Sobels (Ed.), Repair from Genetic Radiation Damage (Pergamon Press, London, $1 9 6 3 \longdiv { \text { . } }$

86. M. H. Patrick, R. H. Haynes, and R. B. Uretz, Radiation Res. 21, 144 (1964).

87. A. Castellani, J. Jagger, and R. B. Setlow, Science 143, 1170 (1964).

88. E. Witkin, J. Cell Comp. Physiol. 58 (Suppl. 1), 135 (1961).

89. R. F. Hill, Biochim. Biophys. Acta 30, 636 (1958).

90. W. Sauerbier, Z. Verenbungslehre 93, 220 (1962).

91. P. Howard-Flanders, R. P. Boyce, E. Simson, and L. Theriot, Proc. Natl. Acad. Sci. U. S. 48, 2109 (1962).

92. R. B. Setlow and W. L. Carrier, Proc. Natl. Acad. Sci. U. S. 51, 226 (1964).

93. R. P. Boyce and P. Howard-Flanders, Proc. Natl. Acad. Sci. U. S. 51, 293 (1964). 
$-51-$

UCRL-11387 Suppl.

94. C. C. Richardson, C. L. Schildkraut, and A. Kornberg, in Cold Spring Harbor Symposia on Quantitative Biology 28, 9 (1964).

95. A. Zampieri and J. Greenberg, J. Bacteriol. 87, 1094 (1964).

96. R. H. Haynes, M. H. Patrick, and J. E. Baptist, Radiation Res. 22, 194 (1964).

97. R. B. Uretz, Radiation Res. 22, 245 (1964).

98. J. T. Lyman, R. H. Haynes, and C. A. Tobias, Radiation Res. 19, 237 (1963).

99. J. T. Lyman, personal communication, 1964.

100. E. L. Powers, R. B. Webb, and B. F. Kaleta, Proc. Natl. Acad. Sci. U. S. 46, 984 (1960).

101. R. B. Uretz, personal communication, 1964. 
This report was prepared as an account of Government sponsored work. Neither the United States, nor the Commission, nor any person acting on behalf of the Commission:

A. Makes any warranty or representation, expressed or implied, with respect to the accuracy, completeness, or usefulness of the information contained in this report, or that the use of any information, apparatus, method, or process disclosed in this report may not infringe privately owned rights; or

B. Assumes any liabilities with respect to the use of, or for damages resulting from the use of any information, apparatus, method, or process disclosed in this report.

As used in the above, "person acting on behalf of the Commission" includes any employee or contractor of the Commission, or employee of such contractor, to the extent that such employee or contractor of the Commission, or employee of such contractor prepares, disseminates, or provides access to, any information pursuant to his employment or contract with the Commission, or his employment with such contractor. 